OPEN ACCESS

Edited by:

Gabi U. Dachs,

University of Otago, Christchurch,

New Zealand

Reviewed by:

Daniel Rabe,

Massachusetts General Hospital

Cancer Center, United States

Laura Soucek,

Vall d'Hebron Institute of Oncology

(NHIO), Spain

Sílvia Casacuberta-Serra,

Peptomyc, Spain,

in collaboration with reviewer $L S$

*Correspondence:

Neil M. O'Brien-Simpson

neil.obs@unimelb.edu.au

Specialty section:

This article was submitted to

Cancer Molecular Targets

and Therapeutics,

a section of the journal

Frontiers in Oncology

Received: 02 October 2021 Accepted: 30 November 2021

Published: 20 December 2021

Citation:

Hourani T, Holden JA, Li W, Lenzo JC, Hadijgol S and O'Brien-Simpson NM

(2021) Tumor Associated Macrophages: Origin, Recruitment, Phenotypic Diversity, and Targeting.

Front. Oncol. 11:788365.

doi: 10.3389/fonc.2021.788365

\section{Tumor Associated Macrophages: Origin, Recruitment, Phenotypic Diversity, and Targeting}

\author{
Tetiana Hourani, James A. Holden, Wenyi Li, Jason C. Lenzo, Sara Hadjigol \\ and Neil M. O'Brien-Simpson *
}

Antimicrobial, Cancer Therapeutics and Vaccines (ACTV) Research Group, Melbourne Dental School, Centre for Oral Health Research, Royal Dental Hospital, The University of Melbourne, Melbourne, VIC, Australia

The tumor microenvironment (TME) is known to have a strong influence on tumorigenesis, with various components being involved in tumor suppression and tumor growth. A protumorigenic TME is characterized by an increased infiltration of tumor associated macrophages (TAMs), where their presence is strongly associated with tumor progression, therapy resistance, and poor survival rates. This association between the increased TAMs and poor therapeutic outcomes are stemming an increasing interest in investigating TAMs as a potential therapeutic target in cancer treatment. Prominent mechanisms in targeting TAMs include: blocking recruitment, stimulating repolarization, and depletion methods. For enhancing targeting specificity multiple nanomaterials are currently being explored for the precise delivery of chemotherapeutic cargo, including the conjugation with TAM-targeting peptides. In this paper, we provide a focused literature review of macrophage biology in relation to their role in tumorigenesis. First, we discuss the origin, recruitment mechanisms, and phenotypic diversity of TAMs based on recent investigations in the literature. Then the paper provides a detailed review on the current methods of targeting TAMs, including the use of nanomaterials as novel cancer therapeutics.

Keywords: tumor associated macrophages (TAMS), solid tumor, peptide, nanotargeting, nanotherapy, cancers, immunotherapies

\section{INTRODUCTION}

The tumor microenvironment (TME) that surrounds cancer cells, plays an important role in carcinogenesis. It is involved in multiple processes including tumor growth, metastasis, and the development of treatment resistance (1). The TME is known to be unique to each tumor type and changes throughout the different stages of tumor development, thus making TME biology a complex field of research. The TME consists of various components, such as tumor stromal cells (cancer associated fibroblasts), blood and lymphatic vasculature, immune cells (macrophages, tumor infiltrating lymphocytes, dendritic cells, etc), and non-cellular components such as extracellular matrix and signalling molecules. The continual interaction of these components along with malignant cells provides a dynamic network for either supporting or suppressing tumorigenesis $(2,3)$. 
Tumor evasion of the immune system is a known "hallmark of cancer" where clinical outcomes have been consistently linked to immune cell populations present within the TME (2). An antitumorigenic TME is characterized by the presence of multiple types of immune cells including $\mathrm{T}$ helper cells of type 1 (Th1), CD8+ cytotoxic T lymphocytes (CTL), M1 macrophages, N1 neutrophils, natural killer cells (NK cells) and dendritic cells (DC). This coincides with proinflammatory bioactive molecules such as; antitumorigenic cytokines [interleukin 2 (IL-2), IL-12, interferon gamma (IFN $\gamma$ )], growth factors [granulocyte-macrophage colony-stimulating factor (GM-CSF) and chemokines (CXC motive chemokine ligand 9 (CXCL9), CXCL10]. Conversely, the predominant immune cell populations in a protumorigenic TME include: M2-like TAMs, T helper 2 cells (Th2), myeloid-derived suppressor cells (MDSC), $\mathrm{N} 2$ neutrophils, tolerogenic dendritic cells (tDC), and T regulatory cells (Tregs). While the protumorigenic bioactive molecules include; protumorigenic cytokines (IL-4, IL-6, IL-10, transforming growth factor beta (TGF- $\beta$ ), IFN $\gamma$ ), angiogenic factors (vascular endothelial growth factor (VEGF), growth factors [GM-CSF, epidermal growth factor (EGF), hepatocyte growth factor (HGF), fibroblast growth factor (FGF)] and chemokines [C-C motif chemokine ligand 2 (CCL2)] $(2,4)$
(Figure 1). The complex structure of the TME means that the presence of certain cell populations and/or biological molecules are not always indicative of tumor progression or suppression (5-11). For example, IFN $\gamma$ is predominantly known for its antitumor activity, however it has been shown to have a protumorigenic property by inducing the upregulation of $\mathrm{PD}$ L1 in tumors (12-14). Another example is GM-CSF which is recognized for its ability to induce antitumor immune responses as well as modulate protumorigenic properties like tumor growth and spread (15).

With the increased interest in the protumorigenic immune TME, more opportunities arise in discovering novel therapeutic targets and in developing potent anticancer therapies. For instance, the recent introduction of immune checkpoint inhibitors (ICI) improved treatment outcomes for many cancer patients and highlighted the importance of the research in this field $(16,17)$. Unfortunately, many cancers become or are non-responsive to ICI and investigations are ongoing to understand underlying cause of resistance (18). Currently, a number of clinical trials are investigating the therapeutic potential of combining ICI with targeting TAMs in order to counteract a protumorigenic TME and overcome ICI resistance (19).

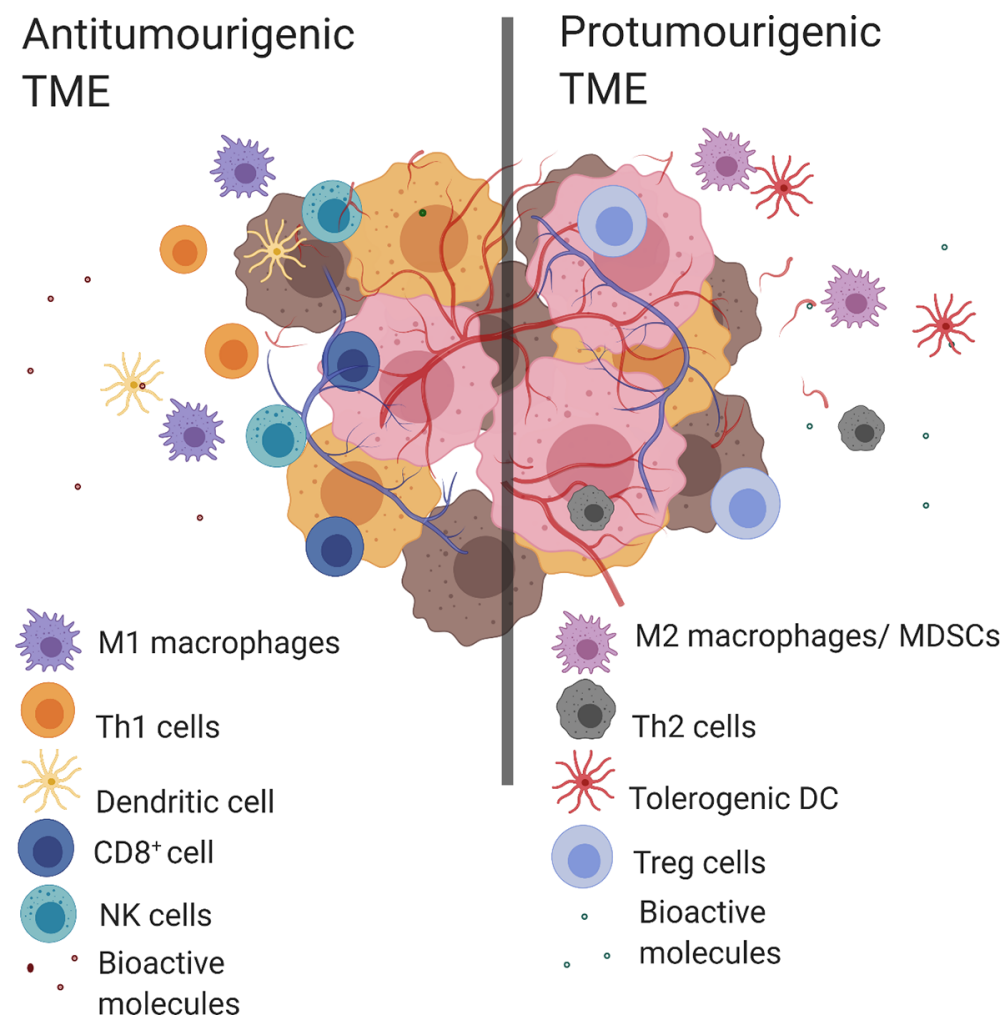

FIGURE 1 Antitumorigenic and protumorigenic TME components. Antitumorigenic and protumorigenic TME have distinct immunologic profiles. Left. An antitumorigenic TME: M1 macrophages, Th1 cells, DC, CD8+ cells, NK cells and bioactive molecules (antitumorigenic cytokines (IL-2, IL-12, IFN $\gamma$ ), growth factor (GM-CSF), chemokines (CXCL9, CXCL10). Right. A protumorigenic TME: M2 macrophages, tolerogenic DCs, MDSCs, Th2 cells, Treg cells and bioactive molecules (protumorigenic cytokines (IL-4, IL-6, IL-10, TGF- $\beta$, IFN $\gamma$ ), angiogenic factors (VEGF), growth factors (GM-CSF, EGF, HGF, FGF) and chemokines (CCL2)). Created with BioRender.com. 
Multiple studies describe the active role of TAMs in tumorigenesis and demonstrate that targeting protumorigenic TAMs is an effective strategy to attenuate tumor progression (20-23). The aim of this paper is to provide a current understanding of macrophage biology in relation to their role in tumor progression, and therapeutic approaches to target TAMs, including a specific targeting with nanomaterials and TAM targeting peptides.

\section{MACROPHAGE HETEROGENEITY, PLASTICITY, AND NOMENCLATURE}

Macrophages are a heterogeneous and complex population of immune cells having roles in host defense against pathogens, maintenance of tissue homeostasis and tissue architecture (24). Macrophages are highly plastic cells and in response to microenvironmental signals such as chemokines and cytokines differentiate/polarize into distinct phenotypes with specific functionality. Multiple populations of macrophages are known to be present within the same microenvironment and each phenotype has a distinctive combination of expressing receptors, secreting chemokines and cytokines (25). A current classification of macrophages is based on their function and response to polarizing agent. Traditionally, unpolarized macrophages are called M0 (naïve) and all other macrophage phenotypes have been divided between M1 (classical) and M2 (non-classical) polarization spectra. This classification also includes M2 subtypes M2a, M2b, M2c, M2d (26) (Table 1). Since the same/similar phenotypes can be generated by several polarizing agents in vitro, Murray et al. suggested to expand macrophage classification by including the activating molecules in macrophage naming. According to this nomenclature, M1 macrophages are subdivided into $\mathrm{M}(\mathrm{LPS}), \mathrm{M}(\mathrm{IFN} \gamma)$ or $\mathrm{M}$ (IFN $\gamma+\mathrm{LPS}), \mathrm{M} 2 \mathrm{a}$ become M(IL-4), M(IL-13) or M(IL-4/IL13), M2b - M(IC+LPS), M2c - M(IL-10) etc (38). Mosser et al. have also proposed to categorize macrophages accordingly to their in vivo functions, such as: (i) host defense, performed by classically activated macrophages induced by IFN $\gamma$, LPS, and TNF, (ii) wound healing, performed by IL-4 and IL-13 activated macrophages, and (iii) immune regulation, performed by regulatory macrophages induced by glucocorticoids, TGF- $\beta$, IC+LPS, IL-10, apoptotic cells, prostaglandins, adenosine and some other stimulants (39). Though the M1-M2 classification system is used extensively, its appropriateness and in vivo applicability are debated, as there are macrophage subsets that express an intermediate phenotype and have markers present from both M1 and M2 polarization states (24). Additionally, there are macrophage phenotypes with novel characteristics (40, 41). Current theorems suggest that the development of an immunologically relevant macrophage classification also depends on an understanding of the macrophage's surrounding microenvironment $(24,38,40)$. Indeed, with increased investigations into macrophage polarizing agents, more novel macrophage phenotypes are being discovered. For example, two recently identified macrophages, M4 and M17, are defined by their polarizing ligands chemokine (C-X-C) ligand 4 (CXCL4) (40) and IL-17 (42), respectively (Table 1). In addition, novel macrophage phenotypes have been discovered by a transcriptome analysis of human macrophages polarized with 28 different stimuli. Interestingly, some of these transcriptomes were matched to the transcriptomes of alveolar macrophages obtained from smokers and patients with chronic obstructive pulmonary disease (COPD) (41).

Overall, traditionally $\mathrm{M} 1$ and M2 polarization states are used to classify macrophages. However, with advancements in medical research it has become evident that in vivo macrophage diversity is more complex. With the increased understanding of macrophage polarizing conditions, more novel macrophage phenotypes are being discovered that not only demonstrate macrophage heterogeneity and plasticity but are also more suitable in vitro models.

TABLE 1 | In vitro macrophage phenotypes and their role in cancer.

\begin{tabular}{|c|c|c|c|}
\hline Phenotype & Activators & Phenotypic Markers/Secreted molecules & Association with cancer \\
\hline $\begin{array}{l}\text { M1 } \\
\text { (classical) }\end{array}$ & $\begin{array}{l}\text { IFN } \gamma / \text { Lps } \\
\text { TNF }\end{array}$ & $\begin{array}{l}\text { CD86, iNOS, CD80, CD40, CD69, MHCII, } \\
\text { CD38, TLR2, TLR4; } \\
\text { IL-12, IL-23, IL-6; }\end{array}$ & Improved patient survival in NSCLC (27) and ovarian cancer (28). \\
\hline $\begin{array}{l}\text { M2a } \\
\text { (M2, } \\
\text { alternative) }\end{array}$ & IL-4/IL-13 & $\begin{array}{l}\text { CD206, CD163, MHCll, Erg2; } \\
\text { TGF- } \beta \text {, IL-10, IL-1RA; } \\
\text { In mouse only: Arg-1, Ym1/2, Fizz1(RELM- } \alpha) \text {; }\end{array}$ & $\begin{array}{l}\text { Lung cancer progression (29). } \\
\text { Stimulated invasion and migration of breast cancer cells (30). }\end{array}$ \\
\hline $\begin{array}{l}\mathrm{M} 2 \mathrm{~b} \\
\text { (regulatory) }\end{array}$ & $\begin{array}{l}\text { Immune } \\
\text { complexes/LPS, } \\
\text { IL-1R }\end{array}$ & $\begin{array}{l}\text { CD86, CD163, MHCII, iNOS; } \\
\text { LIGHT (TNFSF14), CCL1, IL-10, IL-1, IL-6, } \\
\text { TNF- } \alpha\end{array}$ & $\begin{array}{l}\text { Progression of HCC (31). Bevacizumab-resistant triple-negative breast } \\
\text { cancer (32). }\end{array}$ \\
\hline $\begin{array}{l}\mathrm{M} 2 \mathrm{c} \\
\text { (regulatory) }\end{array}$ & $\begin{array}{l}\text { IL-10, } \\
\text { Glucocorticoids, } \\
\text { TGF- } \beta\end{array}$ & $\begin{array}{l}\text { CD163, TLR1, TLR8, CCR2, SR-A (CD204); } \\
\text { IL-10, TGF- } \beta \text {; }\end{array}$ & $\begin{array}{l}\text { Progression of lung cancer (29). } \\
\text { Advanced breast cancer (33). }\end{array}$ \\
\hline $\begin{array}{l}\text { M2d } \\
\text { (angiogenic, } \\
\text { TAMs) }\end{array}$ & $\begin{array}{l}\text { Adenosine/Lps, } \\
\text { IL-6, LIF }\end{array}$ & iNOS, IL-10, IL-12, IL-6, VEGF; & $\begin{array}{l}\text { Tumor angiogenesis (34) } \\
\text { Progression of gastric cancer (35) and HCC (36). Radiation-induced macrophage } \\
\text { infiltration in NSCLC (37). }\end{array}$ \\
\hline M4 & CXCL4 & IL-6, TNF, MMP-7, MMP-12; & Not reported \\
\hline M17 & IL-17 & $\begin{array}{l}\text { TLR2, TLR4; } \\
\text { TNF- } \alpha\end{array}$ & Not reported \\
\hline
\end{tabular}




\section{TAMs Origin and Recruitment}

Macrophages have two distinct developmental pathways. Briefly, tissue-resident macrophages are developed from embryonic precursors (fetal yolk sack or fetal liver progenitors) and monocyte-derived macrophages are developed from bonemarrow haemopoietic cell progenitors (43). Tissue-resident macrophages are widely distributed in the body and, depending on their location, are called osteoclasts in bone, alveolar macrophages in lungs, microglial cells in central nervous system and Kupffer cells in liver. Monocyte-derived macrophages serve as a reservoir for macrophage replenishment and are recruited in pathology (25). Under physiological conditions, tissue resident macrophages and monocyte-derived macrophages have a distinct tissue distribution: (i) both subsets are present in liver, pancreas, lung, heart, kidney and spleen; (ii) only tissue-resident macrophages (yolk sac derived) are found in brain; (iii) monocyte-derived macrophages predominate in intestines and dermis $(44,45)$.

Compared to tissue homeostasis, cancer is characterized by increased monocyte recruitment and/or expansion of tissue- resident macrophages with both populations involved in tumorigenesis (25) (Figure 2). For example, in a murine model of pancreatic ductal adenocarcinoma (PDAC), the expansion of the tissue resident-macrophages population ( $>29$ fold) was observed (44). Both, tissue resident interstitial macrophages and recruited monocyte-derived macrophages were found in murine TC-1 lung carcinoma (46). Chen et al. reported that recruited monocyte-derived macrophages accounted for $85 \%$ of the total TAMs in glioblastoma (47). Recruitment of monocytederived macrophages to liver was also seen in hepatocellular carcinoma (48)

Various pathways are involved in monocyte recruitment to the tumor including monocyte recruiting cytokines, chemokines, and growth factors. The most prominent recruitment ligand/ receptors are M-CSF/CSF-1R, CCL2/CCR2, CX3CL1/CX3CR1, CCL3/CCR1, CCL3/CCR5, CCL5/CCR5, and VEGF-A/VEGFR1 ligand-receptor interactions (49).

M-CSF (also called CSF-1) is an important molecule involved in recruitment and M2 polarization of monocytes, and in selfrenewal of tissue-resident macrophages $(50,51)$. High levels of
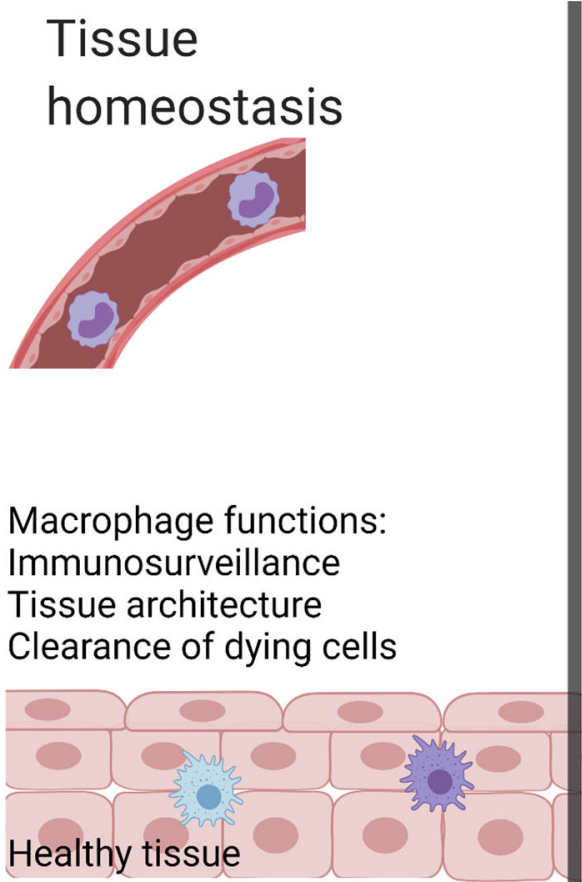

Monocytes

\section{Cancer}

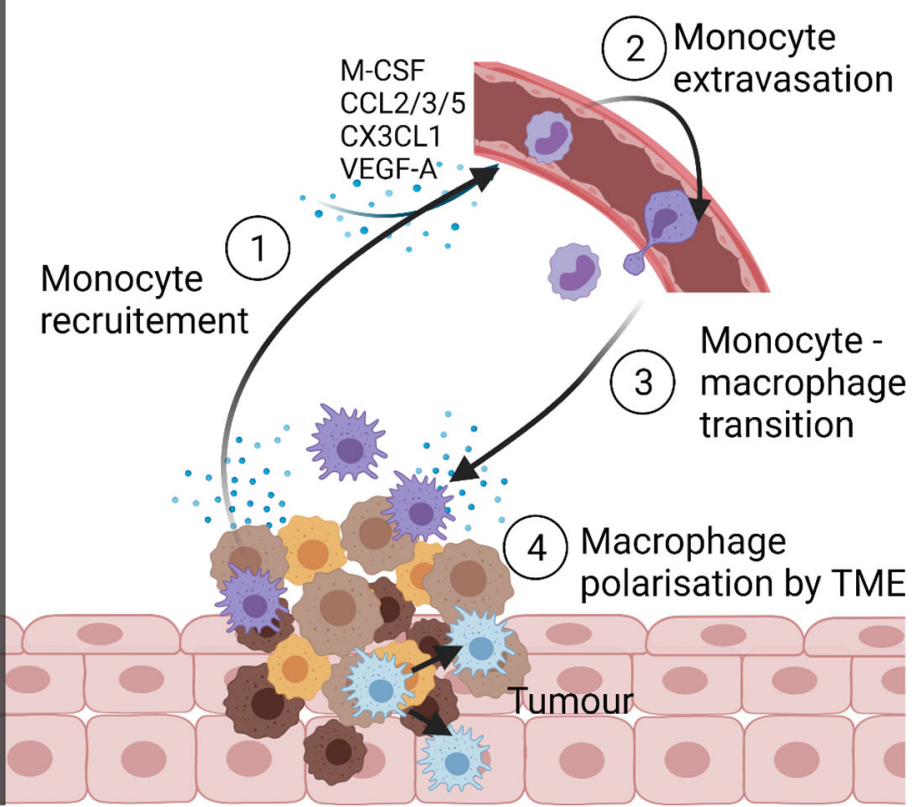

\section{Tissue resident macrophages}

FIGURE 2 | Macrophage populations in homeostasis and cancer. In health, macrophages present within tissues are tissue-resident macrophages and/or monocytederived macrophages. These macrophages maintain tissue homeostasis by performing numerous functions like immunosurveillance, clearance of senescent and apoptotic cells, and maintenance of tissue architecture. The TME of cancer is highly infiltrated with macrophages due to the increase in monocyte recruitment from the blood stream and/or self-proliferation of tissue-resident macrophages. The TME derived monocyte recruiting molecules (M-CSF, CCL2, CX3CL1, CCL3, CCL5, and VEGF-A) stimulate monocyte extravasation into the TME, where monocytes are transformed to monocyte-derived TAMs. Created with BioRender.com. 
expression of M-CSF was found in advanced upper tract urothelial carcinoma (52), breast cancer (53), esophagus SCC (54), gastric cancer (55).

Colony-stimulating factor 1 receptor (CSF-1R) has two ligands, macrophage colony-stimulating factor (M-CSF) and IL-34, and both are involved in various protumorigenic processes. IL-34 has two effects on tumor cells and the TME, being protumorigenic in lung cancer and ovarian cancer, but having an antitumorigenic role in luminal and Her2+ breast tumors. The protumorigenic effects of IL-34 on TAMs include monocyte recruitment, polarization, and survival in the TME (56).

The chemokine CCL2 is a strong chemoattractant for CCR2+ monocytes (57) and its overexpression was reported in progressing breast cancer (58), prostate cancer (59), oral squamous cell carcinoma (OSCC) (60), liver cancer (61), and colorectal cancer (CRC) (62). A number of studies have shown a correlation between CCL2 expression and TAM infiltration in clear cell renal cell carcinoma (63) and esophageal cancer (64). CCL8, another ligand of CCR2, was found to be highly overexpressed in human cervical cancer and involved in TAMs recruitment to hypoxic areas (65).

Another chemokine involved in monocyte recruitment is CCL3. Interestingly, CCL3 has diverse functions in the TME as it is secreted by a broad range of immune/non-immune cells and, in addition, CCL3 binds to various cells expressing CCR1, CCR5, and CCR3 $(5,66)$. Increased levels of CCL3 have been reported in colorectal (67), esophageal (68), and endometrial cancers (5). CCL3 secretion by TAMs was found to be induced by CCL2/ CCR2 and IL-33, with these TAMs reported to mediate metastatic spread in different tumor models $(66,68,69)$. For example, the CCL3/CCR1 axis was found to mediate macrophage recruitment during the formation of early metastatic niches in a mouse E0771-LG breast cancer model $(66,69)$, and CCL3/CCR5 mediated macrophage recruitment to the metastatic site in murine Renca renal cell carcinoma model (70). In addition, CCL3 derived from TAMs was reported to promote esophageal cancer cells (TE-8 and TE-9) migration and invasion via interaction with their CCR5 receptor (68).

CCL5 is also a known potent monocyte chemoattractant. Similar to CCL3, CCL5 is expressed by a variety of cell types, and has a number of binding receptors including CCR1, CCR3, CCR5, G-protein coupled receptor 75 (GPR75), and CD44 (5, 71). High expression of CCL5 has been correlated with poor prognosis in many cancers (5), including glioblastoma (71) and breast cancer (72). Indeed, CCL5 was shown to recruit and mediate M2-like TAM polarization, with this being linked to glioblastoma progression (71), as well as to recurrence and metastasis in breast cancer $(73,74)$. Apart from monocyte recruitment, CCL5 has a direct effect on tumor cells, supporting tumor cells migration, invasion, and survival (71, 74). High CCL5 expression was also associated with increased TILs such as CD8+ T cells, NK cells, and M1 macrophages in triple negative breast cancer. This study reported that patients with low CCL5 and TILs had an increased residual tumor size (75).
The CX3CL1/CX3CR1 axis is also an important monocyte recruitment pathway. In human colon carcinoma, CX3CR1+ TAM infiltration was associated with poor prognosis as these TAMs were found to be proangiogenic and prometastatic (76). The CX3CL1/CX3CR1 axis was also involved in macrophage recruitment in breast cancer (77). In addition, CX3CR1+ and CCR2+ recruited macrophages were also found to support Lewis lung carcinoma progression (78). While predominantly CX3CL1/CX3CR1 signalling is related to tumor progression, inactivation of the CX3CL1/CX3CR1 axis was shown to enhance glioblastoma development. In fact, brain tissue homeostasis is maintained by CX3CR $1+$ microglia which interact with CX3CL1+ neurons (79).

TAM recruitment to the hypoxic TME is also mediated by VEGF-A, endothelin-2, and EMAPII. Once recruited, TAM migratory receptors become downregulated, which prevents their further migration. Within a hypoxic TME, TAMs participate in angiogenesis and tumor spread due to the upregulation of hypoxia-inducible factor (HIF)- $1 \alpha$ and HIF- $2 \alpha$ (80). HIF- $1 \alpha$ is known to increase TAMs infiltration and induces epidermal growth factor (EGF) production in TAMs, which in turn promotes metastasis (81). Further, both HIF-1 $\alpha$ and HIF$2 \alpha$ upregulate angiogenic molecules VEGF, IL- 6 , and the tyrosine-protein kinase receptor (Tie2) receptor in TAMs, thus promoting tumor angiogenesis $(81,82)$.

It is clear that tissue-resident-macrophage expansion and new monocyte recruitment are critical for the development of multiple solid cancers. Indeed, these studies suggest that the major monocyte recruiting pathways (M-CSF/CSF-1R, CCL2/ CCR2, CCL3/CCR1, CCL3/CCR5, CCL5/CCR5 and CX3CL1/ CX3CR1) enable tumor survival by supplying the TME with protumorigenic TAMs. Thus, a suppression of monocyte/ macrophages recruitment is a potential therapeutic strategy to eliminate or reduce TAMs involvement in tumorigenesis.

\section{Protumorigenic Tumor Associated Macrophages (TAMs)}

Biomolecules derived from the TME and cancer cells have a direct effect on macrophage polarization. Although at the early stages of tumor formation macrophages within the TME predominantly express a proinflammatory M1 phenotype, tumor progression is associated with increased infiltration of anti-inflammatory M2 polarized TAMs (83). It is known that the TAM population within the TME is phenotypically heterogenous $(25,84)$ and the overall number of TAMs accumulated within a tumor is not considered in estimation of clinical prognosis. However, the ratio of $\mathrm{M} 1 / \mathrm{M} 2$ is considered an important prognostic marker (6-11). A low M1/M2 TAM ratio is associated with tumor progression and poor prognosis, while a high $\mathrm{M} 1 / \mathrm{M} 2$ ratio tends to correlate with positive outcomes in ovarian cancer (6), gastric cancer (7), CRC (8), osteosarcoma (9), lung cancer (10) and OSCC (11). Multiple studies showed that M2 TAMs have strong roles in promoting of tumor growth (85), angiogenesis $(86,87)$, modification of extracellular matrix (88), inhibition of anti-tumor immunity (25), metastasis (89), chemoresistance (90) and recurrence (91) (Figure 3). 


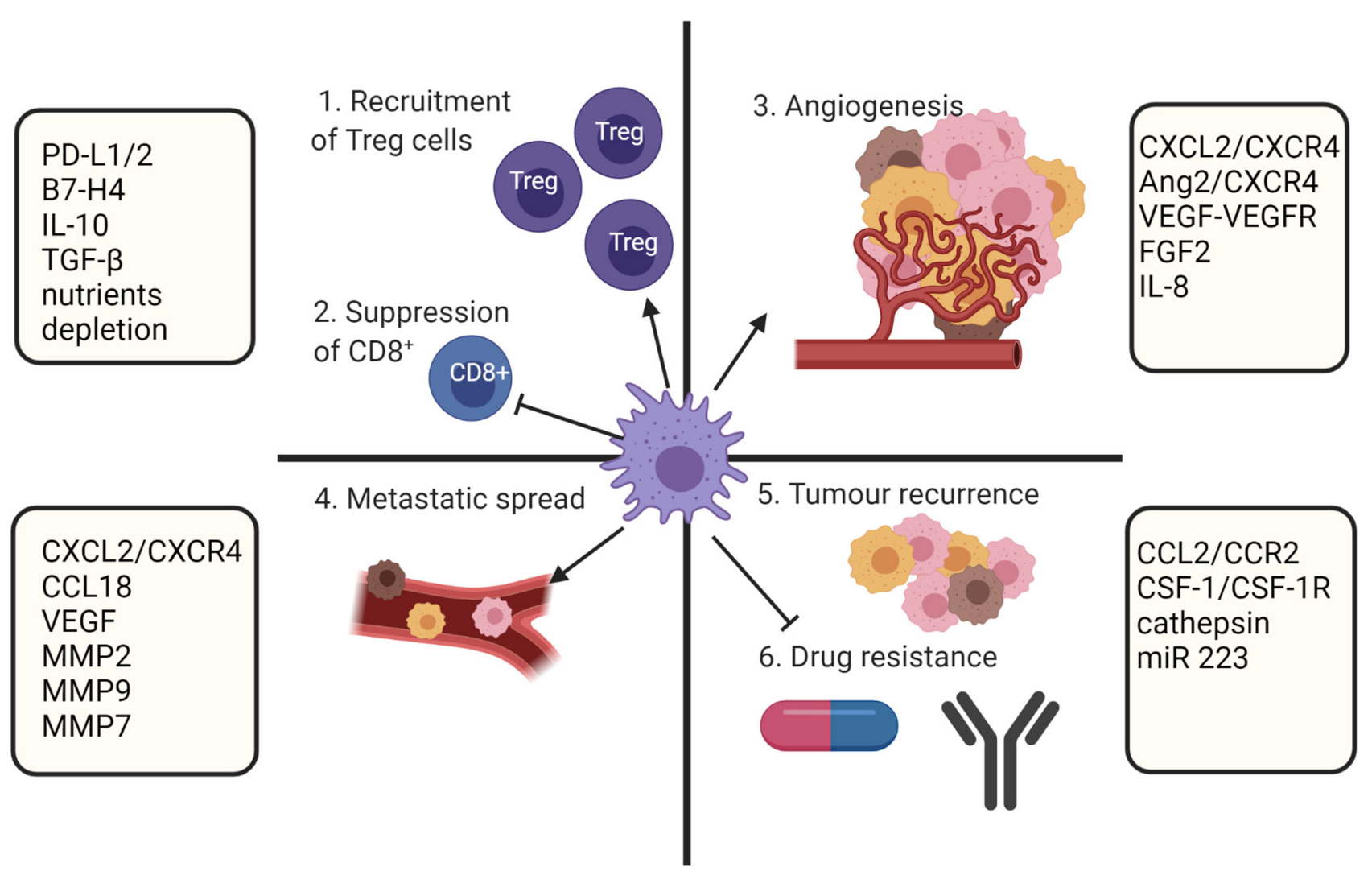

FIGURE 3 | TAMs role in supporting tumor growth. TAMs mediate immunosuppression by recruiting Treg cell and inhibiting CD8+ T cells. In addition, TAMs participate in metastatic spread, angiogenesis, and drug resistance. Created with BioRender.com.

TAMs mediated immunosuppression severely disrupt the effector cell functions required for tumor clearance. Some of the known strategies by which TAM mediate immune evasion include: (i) the upregulation of checkpoint inhibitors such as programmed cell death ligand 1 (PD-L1), PD-L2 and B7 superfamily member 1 (B7-H4) which deactivates effector CTLs via interaction with their receptor PD-1. Increased expression of PD-L1 and PD-L2 within the TME has been associated with poor prognosis in multiple solid cancers (92) and CTL dysfunction was mediated by B7-H4 expressing TAMs in ovarian cancer (93); (ii) production of immunosuppressive cytokines IL-10 and TGF- $\beta$ that affect multiple immune cells. Both cytokines are known to induce an anti-inflammatory phenotype in monocytes and macrophages and inhibit CD4+ and CD8+ T cell proliferation and cytokine production $(94,95)$. In addition, TGF- $\beta$ induces Treg cells and prevents Th1 polarization (95). Interestingly, TAM derived IFN $\gamma$ has been shown to induce PD-L1 expression in lung cancer and by this mechanism supported tumor progression (96); and (iii) CTL exclusion from intra-tumoral environment. The known TAMs mechanisms are stimulation of tumor stroma fibrosis by granulin secretion and depletion of nutrients (97). Overall, TAMs are equipped with multiple mechanisms to generate and support an immunosuppressive TME.
TAMs are known to be strongly involved in tumor angiogenesis and it has been reported that the hypoxic environment of the TME aids this TAM function. Angiogenic TAMs are typically located in hypoxic avascular tumor areas (98) with recruitment and maintenance of angiogenic function mediated by CXCL12-CXCR4, angiopoietin-2 (Ang2)-Tie2, and VEGF-VEGFR pathways (87). Under hypoxic conditions TAMs are known to upregulate HIF- $1 \alpha / 2 \alpha$ (80) which are inducers for angiogenic molecules like VEGF, FGF2, CXCL8, IL-8, and the Tie2 receptor (80-82).

Some TAM phenotypes have a distinct role in tumor metastasis. For example, CXCR4+ TAMs are involved in metastatic spread via promotion of epithelial-to-mesenchymal transition (EMT) and cancer stem cells development in OSCC (99), luminal B breast cancer (100) colorectal cancer (101), nonsmall cell lung cancer (NSCLC) (102), hepatobiliary cancers (103). These TAMs are recruited to the tumor site by stromal cell derived factor 1 (CXCL12), a chemokine produced within the TME (104). Metastasis was also supported by CCL18 secreting TAMs in pancreatic ductal adenocarcinoma (PDAC) (105), head and neck squamous cell carcinoma (HNSCC) (106), osteosarcoma (107), gallbladder cancer (108), hepatocellular carcinoma (HCC) (109), NSCLC (110), gastric cancer (111). CCL18 is a chemokine involved in immune tolerance by the 
recruitment and generation of immune cells like tolerogenic DCs, Th2, M2 macrophages and suppression of effector T lymphocytes. In addition, exposure of tumor cells to CCL18 promoted EMT cell motility and invasion (112). TAMs are known to produce proteolytic enzymes like matrix metalloproteinases (MMP2, MMP9, MMP7), serine proteases, and factors involved neovasculature formation (VEGF, MMP9) to enhance metastasis (113). As such, TAM derived MMP9 has been associated with enhanced invasion and migration in HCC (114), gastric cancer (115), melanoma (116), colon cancer (117), and estrogen receptor positive breast cancer (118).

Tumor recurrence has been shown to be associated with increased TAM infiltration in the TME. For example, increased CD11b+ myeloid cells infiltration was observed in early recurrent head and neck cancer (119) and in recurrent glioblastoma (120). In addition, reduced recurrence-free survival was associated with increased stromal CD68+ CD163+ TAMs in basal-like breast cancer (121), and with increased tumor center CD68+ CD163+TAMs in colorectal cancer (122).

TAM mediated chemoresistance is a significant challenge in tumor treatment as it limits patients' treatment options and contributes to tumor recurrence. For example, high infiltration of CD68+ and CD163+ TAMs were associated with a poor response to neoadjuvant chemotherapy in oesophageal cancers (123), and to immunotherapy resistance in bladder cancer $(124,125)$. Some of the known mechanisms applied by TAMs to mediate chemoresistance are the inhibition of tumor cell death (126), production of cathepsin cysteine proteases (127), and TAMs mediated upregulation of chemoresistance-associated pathways in tumor cells (128). Oxaliplatin resistance, measured by the reduction in tumor cell death and an increase in autophagy, was observed in SMMC-7721 and Huh-7 human HCC cell lines cocultured with PMA-treated THP-1 macrophages (126). In PyMT cells, TAMs derived cathepsin was shown to inhibit paclitaxel mediated tumor cells death (127). Cisplatin resistance has been shown to be mediated by TAMs derived miR-223 exosomes which activated the PTEN-PI3K/AKT pathway in SKOV3 human epithelial ovarian cancer cells (128). In addition to chemoresistance, TAMs have been reported to be involved in radiotherapy resistance via activation of monocyte recruitment pathways. Increased TAMs infiltration and a restored protumorigenic TME were observed as a result of radiotherapy induced activation of CCL2/CCR2 axis in pancreatic ductal adenocarcinoma (129) and of the CSF-1/CSF-R axis in glioblastoma (120).

To date there have been several investigations that have reported on TAM phenotypes present in a specific TME and this knowledge is proving invaluable for the understanding the role of TAMs in tumor development and discovery of an effective treatment (130). For example, in breast cancer the following macrophage phenotypes and their functions have been described: (i) M2a TAMs mediated the persistence of the dormant breast cancer cells (131), (ii) M2a/M2c (CD163+) TAM infiltration was associated with poor differentiation, fast proliferation, histological ductal type, and estrogen receptor negativity in primary breast cancer (132); (iii) CCR6 expressing TAMs were involved in the initiation and early stage tumorigenesis of breast cancer in vivo (133), (iv) high infiltration of SIGLEC1+ CCL8+ TAMs was shown to be associated with shorter disease-specific survival in estrogen receptor positive breast cancer (134), (v) high infiltration of CCR5-expressing macrophages was found in residual epidermal growth factor receptor 2 (Her2) positive breast tumors (73).

In a lung cancer (A549) xenograft model M0, M2a and M2c TAMs were found to promote cancer invasiveness, while M1 macrophages contributed to tumor suppression, reduced angiogenesis and sensitivity to chemotherapy (29). M2a TAMs were found to also be involved in A549 tumor cell migration via direct contact with tumor cells (135).

In HCC, a high infiltration of CD86low/CD206high (defined as M2) TAMs correlated with increased tumor aggressiveness, poor overall survival (OS) and increased tumor time to recurrence (TTR) in $\alpha$-fetoprotein-negative patients. Conversely, a high number of CD86high/CD206low (M1 defined) TAMs was associated with favorable OS and TTR (136). M2c TAMs were seen in early stages of HCC in C57BL/ 6 male mice on high fat-high cholesterol-high sugar diet treated with a hepatocarcinogen (diethyl nitrosamine) (137). M2b (defined as CD14+CD68+CCL1+IL-12-IL-10+iNOS-) macrophages were also found as a dominant population in advanced HCC (31).

Immunohistochemical analysis of OSCC showed significant TAMs infiltration compared to healthy tissues (138) and the presence of CD68+CD163+(M2) TAMs or CD206+ (M2-like) TAMs were associated with poor overall survival $(139,140)$. In addition, CD163+ (M2) TAMs were associated with primary HPV-negative HNSCC (119).

Overall, data accumulated through several different cancer models suggest that TAMs are a heterogeneous group of cells with multiple mechanisms involved in supporting of tumor progression. Studies indicate that increased infiltration of M1 macrophages, that are pro-inflammatory and equipped with many different cytotoxic molecules important in suppressing tumorigenesis. Alternatively, the predominance of alternative macrophage phenotypes, of any M2 subtype, compromises tumor suppression. Indeed, tumorigenesis is a complicated process with TME being variable between different tumor types and/or tumor stages. And that is why studies looking at polarized macrophage phenotypes report variety of TAMs phenotypes. It is clear, however, that more investigations are needed to identify the TAMs phenotypes in specific TME and possible interplay between these populations for the development of effective therapeutic strategies targeting TAMs.

\section{TAM Targeting Strategies: Strategies in Targeting TAM Recruitment}

Considering the various roles of TAMs in tumorigenesis, significant research effort has focused on targeting of protumorigenic TAMs as potential cancer therapies. Among the widely applied strategies are suppression of TAM recruitment, phenotypic reprograming towards antitumorigenic M1, and TAMs depletion (141) (Figure 4). 


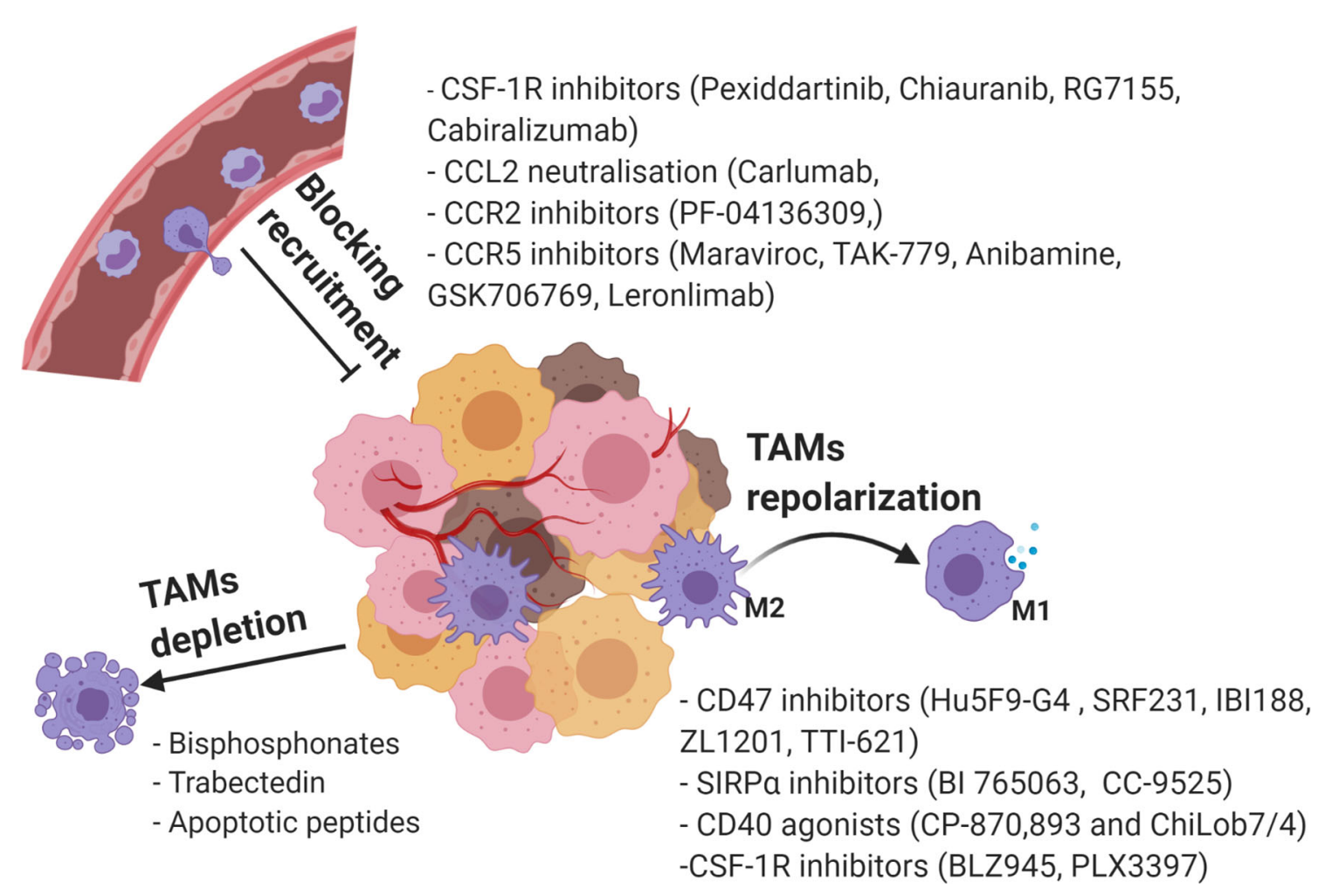

FIGURE 4 | Current strategies in targeting TAMs as a novel cancer therapy. Created with BioRender.com.

The inhibition of monocyte-derived macrophage recruitment is heralded as a promising strategy to reduce the tumor associated TAMs population and to boost an anti-tumor response. The M-CSF/CSF-1R, CCL2/CCR2, CCL5/CCR5, and CX3CL1/CX3CR1 pathways discussed above are the main targets that show potential in tumor therapy (142).

Several monoclonal antibodies and small molecule inhibitors of CSF-1R are under development as a monotherapy or in combination with other therapeutic agents. The FDA approved small molecule inhibitor of CSF-1R Pexidartinib (PLX-3397), used for the treatment of tenosynovial giant cell tumor (143), has been further investigated in multiple clinical trials for treatment of other solid tumors. The recent phase Ib clinical trial of PLX3397 in combination with paclitaxel (a chemotherapeutic) in patients with advanced solid tumors reported effective blockage of CSF-1R measured by the decline in peripheral blood monocytes and increase of CSF1 levels in plasma. Complete response and partial response were seen in $3 \%(n=1)$ and $13 \%$ $(n=5)$ of patients, respectively. However, PLX-3397 does have side effects; $70 \%$ of patients $(n=38)$ reported Grade 3-4 adverse effects, which were hematological toxicities (anemia and neutropenia) and non hematological (hepatotoxicity due to possible effect on Kupffer cells and hypertension) (144).

Chiauranib (CS2164), another small molecule targeting CSF$1 \mathrm{R}$ and angiogenesis-related kinases (VEGFR2, VEGFR1,
VEGFR3, PDGFR $\alpha$ and c-Kit), showed significant antitumor activity in several human xenograft models (145). Currently Chiauranib is being investigated in two ongoing clinical trials on solid tumors (www.clinicaltrials.gov) (ClinicalTrials.gov Identifiers: NCT04830813, NCT03974243) and one Phase I completed trial (ClinicalTrials.gov Identifier: NCT02122809) that has confirmed its safety and favourable pharmacokinetics (146).

Several CSF-1R blocking antibodies were also developed and investigated in clinical trials as an anti-cancer therapy. A CSF-1R blocking monoclonal antibody RG7155 was shown to reduce CSF-1R+CD163+ TAMs and peripheral blood CCR2+ monocytes in phase I clinical trial in patients with diffuse-type giant cell tumor (ClinicalTrials.gov identifier NCT01494688) (147). Also, safety and pharmacodynamic activity of CSF1R inhibitor cabiralizumab was reported in phase I clinical trial testing a combination of CD40 agonist APX005M (sotigalimab) and cabiralizumab with or without PD-1/PD-L1 inhibitor nivolumab in PD-1/PD-L1 resistant advanced cancer patients (ClinicalTrials.gov Identifier: NCT03502330) (148).

CSF-1R blocking agents are also being investigated for synergistic effects with current cancer therapeutics in preclinical studies. For instance, an increase in doxorubicin potency was observed in combination with BLZ945 in mice ovarian cancer model (149) and PLX3397 in mice castration- 
resistant prostate cancer (150). Halbrook et al. also reported that a combination of gemcitabine and CSF-1R inhibitor AZD7507 showed better treatment outcomes in vivo (151).

The blocking of the CCL2/CCR2 axis is also under investigation in multiple clinical studies with variable therapeutic outcomes. For instance, Carlumab (CNTO888), an IgG1k monoclonal antibody that binds to CCL2 showed low therapeutic effect with an increase in free CCL2 levels in phase I trials in patients with solid tumors (152) and in a phase 2 study in metastatic castration-resistant prostate cancer (153). On the other hand, targeting the CCR2 receptor was shown to be more promising, as the combination of a CCR2 inhibitor (PF04136309) with FOLFIRINOX (oxaliplatin and irinotecan plus leucovorin and fluorouracil) improved clinical outcomes in patients with borderline respectable and locally advanced pancreatic adenocarcinoma in a phase I clinical trial (Clinical Trials.gov Identifier: NCT01413022). In the PF-04136309 with FOLFIRINOX combined treatment group, control of tumor growth was seen in 32 out of 33 patients with significant reduction in tumor markers. In addition, there was a decrease of circulatory CCR2+ monocytes, an increase of bone marrow CCR2+ monocytes, a reduction of TAMs in tumor tissues and modulation of the TME (increase in IL-12 and TGF- $\alpha$, and a decrease in IL-10, TGF-b, IL-13) (154). In metastatic PDAC, the combination of PF-04136309 with nab-paclitaxel and gemcitabine was shown to have an increase pulmonary toxicity in Phase Ib (Clinical Trials.gov Identifier: NCT02732938) (155). Though, the CCL2/CCR2 axis is an important target for exploration, Kitamura et al. showed that blocking CCL2/CCR2 axis downstream molecules could be more efficient. The study found that CCL2 recruited metastasis-associated macrophages (MEMs) which accumulated in metastatic sites via activation of the CCL3/CCR1 axis. The suppression of the CCL3/CCR1 axis reduced MEMs accumulation with no effect on circulating monocytes, resident macrophages and CD11b+lung macrophages numbers, indicating that targeting the CCL3/ CCR1 axis may have high treatment specificity (69).

Targeting the CCL5/CCR5 axis has been shown to be a potent strategy to limit TAM recruitment and modulate TAM phenotype. For example, antitumor responses were observed after treatment with CCR5 and CCL1 inhibitors such as CCL5 and CCR5 blocking antibodies, and CCR5 antagonists (Maraviroc, TAK-779, Anibamine, and GSK706769) (156, 157). Blocking the CCR5 receptor with either Maraviroc, CCL5 neutralizing antibody, or CCLR5 blocking antibody was investigated in human colorectal cancer explant model. This study found that inhibition of the CCL5/CCR5 axis induced M1like TAMs polarization, which mediated antitumor responses. Further investigation of Maraviroc in a pilot clinical trial (MARACON) (ClinicalTrials.gov identifier: NCT01736813) in patients with advanced metastatic colorectal cancer showed therapeutic efficiency with a tumor control rate of $80 \%$ (4 out of 5 patients had partial response or stable disease) and mild side effects (158). In a preclinical study, Maraviroc administration lowered F4/80+ TAM numbers and decreased tumor growth in metastatic BM1 MDA-MB-231 human triple negative breast cancer (74). Among CCR5 blocking antibodies, a humanized anti-CCR5 Leronlimab in combination with Carboplatin is currently under investigation in phase $1 \mathrm{~b} / 2$ clinical trial ClinicalTrials.gov identifier: NCT03838367) for patients with CCR5+ metastatic triple negative breast cancer (159).

Another potential target to prevent macrophage recruitment is to block the CX3CL1/CX3CR1 pathway. Though several CX3CL1/CX3CR1 blocking agents have been developed (160162) and anti-tumor activity was reported for CX3CR1 receptor agonists JMS-17-2 and KAND567 (162, 163), the effect of CX3CL1/CX3CR1 pathway inhibition on TAMs has not been explored.

Overall, targeting TAMs recruitment with small molecules or antibodies has been shown to be a promising treatment technique that can be used as a monotherapy or combination therapy with standard treatment therapeutics. However, given the need to address the side effects in targeting macrophage recruitment other strategies for targeting TAMs are under investigation.

\section{TAM Targeting Strategies: Strategies to Re-Polarize TAMs Towards an Anti-Tumorigenic Phenotype}

Macrophage plasticity can also be used as an opportunity to treat cancer by repolarizing TAMs to become anti-tumorigenic. This strategy has already been shown to be possible as the FDAapproved cancer chemotherapy paclitaxel and sorafenib can repolarize TAMs $(164,165)$.

Preclinical and clinical data indicates that enhancement of phagocytosis by TAMs promotes tumor cell clearance and antigen presentation (166). Tumor cells evade macrophage phagocytosis by expressing CD47 that sends "do not eat me signal" to phagocytic cells via interaction with macrophage signal regulatory protein alpha $(\mathrm{SIRP} \alpha)$ receptor. $\mathrm{CD} 47$ was found to be present in numerous haematological and solid tumor types and its expression was associated with reduced survival (167). For that reason, blocking the CD47-SIRP $\alpha$ axis has been widely investigated in cancer treatment with the reported treatment effects being enhancement of tumor cell phagocytosis, TAM repolarization towards an M1 phenotype, increased DC mediated antigen presentation to CD4 and CD8 T cells, enhancement of NKmediated Antibody Dependent Cellular Cytotoxicity and caspaseindependent tumor cells apoptosis (168). Currently, there are few anti-CD47 antibody therapeutics, anti-SIRP $\alpha$ antibody therapeutics or recombinant SIRP $\alpha$ protein in preclinical and clinical studies. The clinical results of CD47-SIRP $\alpha$ disruption was evaluated in Phase I trial of Hu5F9-G4 (5F9) (ClinicalTrials.gov identifier: NCT02216409), a humanized IgG4 anti-CD47 antibody in patients with advanced solid tumors and lymphomas. Treatment was well tolerated and antitumor activity was observed in two patients with clear cell ovarian and fallopian tube carcinomas. However, a few adverse effects were observed in the initial stages of treatment, such as transient anemia, observed in $57 \%$ of patients after the initial priming dose. This was an anticipated side effect, because CD47 is expressed on erythrocytes (RBCs). Stabilization of 
hemoglobin levels was maintained by rapidly released young RBCs which are resistant to 5F9 due to the lack of CD47 on their surface (169). Preliminary data of the Phase $1 / 1 \mathrm{~b}$ clinical trial (Clinical Trials.gov Identifier: NCT03512340) reported the safety and tolerability of SRF231, a fully human IgG4 anti-CD47 antibody, in patients with advanced solid and hematological tumors. Unfortunately, complete or partial response from treatment has not been observed, but, participants had prolonged stable disease (170). Three more anti-CD47 antibodies, IBI188 (ClinicalTrials.gov Identifier: NCT03763149 and NCT03717103), ZL1201 (ClinicalTrials.gov Identifier: NCT04257617), TTI-621 (ClinicalTrials.gov Identifier: NCT02663518, NCT02890368) are in Phase I clinical trials (www.clinicaltrial.gov) with no reported results as of the time of publishing.

Two other, monoclonal antibodies directed against the CD47 receptor SIRP $\alpha$ (BI 765063 and CC-95251) are both under Phase I investigations (ClinicalTrials.gov Identifier: NCT03990233, ClinicalTrials.gov Identifier: NCT03783403 respectively). Though no clinical data is available regarding targeting $\operatorname{SIRP} \alpha$ with antibodies, a possible neurological side effect could be anticipated as SIRP $\alpha$ is expressed on neurons (171). The efficiency of SIRP $\alpha$ fusion proteins is also under investigation in Phase I clinical trials: TTI-621 (ClinicalTrials.gov Identifier: NCT02663518) and ALX148 (Clinical Trials.gov Identifier: NCT03013218) as a monotherapy or in combination with other treatment agents.

Other methods to enhance TAM antitumor activity are also under investigation. For example, the effectiveness of antigen presentation to effector lymphocytes is strongly dependent on CD40/CD40L binding. CD40 is a receptor present in antigen presenting cells (APCs) including macrophages and its ligand, CD40L is expressed on CD4 T cells, B cells and NK cells and memory CD8 T cells. Stimulation of CD40 receptor on APCs was shown to enhance antitumor immunity in preclinical and clinical studies (172-175). Several approaches to activate CD40/CD40L are under investigation: targeting $\mathrm{CD} 40$ by recombinant agonistic CD40 antibodies or targeting CD40L by using recombinant $\mathrm{CD} 40 \mathrm{~L}$ or adenovirus vectors carrying CD40L gene (172). Among the most studied CD40 agonists are CP870,893 and ChiLob7/4. The CD40 agonist CP-870,893, a fully human monoclonal antibody in combination with gemcitabine, was shown to be well tolerated and induced the development of antitumor immunity in patients with advanced pancreatic cancer (Clinical Trials.gov Identifier: NCT00711191) (173). Antitumor immunity was also induced when the CD40 agonist CP-870,893 was used in combination with carboplatin and paclitaxel in advanced melanoma and other solid tumors patients, such as hormone-independent prostate cancer, renal cell carcinoma and ovarian cancer patients (174). A phase I clinical trial using the IgG1 chimeric anti-CD40 antibody ChiLob7/4 found it to be well tolerated in patients with various tumors and 15/29 patients showed median 6 months disease stability (ClinicalTrials.gov Identifier: NCT01561911) (175).

Another promising strategy to modulate protumorigenic TAMs is to inhibit CSF-1R. Though the CSF-1/CSF-1R pathway is required for TAM recruitment and survival, the inhibition of CSF-1R by BLZ945 was shown to repolarize TAMs in a glioblastoma multiforme mouse model. In addition to the reduction in M2 associated gene expression ( $A d m, A r g$, Mrc1, F13a1) in TAMs, this study observed multiple therapeutic effects from BLZ945 treatment, such as reduced tumor aggressiveness and increased animal survival. The effects on TAM survival and polarization were found to be mediated by tumor derived factors, these being IFN $\gamma$ and GM-CSF (176). TAM repolarization and consequent tumor suppression were also observed after treatment with another CSF-1R inhibitor, PLX3397, in a mouse glioblastoma model (177). Interestingly, both studies reported that treatment with CSF-1R inhibitors did not reduce TAM numbers in the TME, however, microglia depletion was seen in the surrounding brain tissues $(176,177)$. Antitumor activity and modulation of TAMs phenotype were observed after PLX3397 administration in a hepatocellular carcinoma mouse model, where TAM repolarization was mediated by tumor derived CSF-2 (178). Collectively, these studies indicate the potential of CSF-1R targeting to block M2like TAM polarization, however, off-target effect such as the suppression of macrophages in healthy tissues may be a side effect to be investigated.

Other promising treatment targets include; M2 specific scavenger receptor MARCO, which was associated with poor prognosis in breast cancer, metastatic melanoma and NSCLC (179); PI3K $\gamma$ signalling that mediates immunosuppressive reprograming of macrophages (180); Lrg4/Rspo-1 axis that was shown to support M2 polarization (181); and tumor-derived exosomes that have been shown to support M2 TAMs polarization and metastasis $(182,183)$.

Overall, repolarization of macrophages is showing promise as a new therapeutic strategy in cancer treatment. Though clinical data on the treatment efficiency of repolarizing agents is limited, it is clear that CD47-SIRP $\alpha$, CD40/CD40L, and CSF-1/CSF-1R molecular pathways are involved in tumor survival and progression. Thus, antitumor immunity can potentially be boosted by reprogramming M2 macrophages to more M1-like phagocytic cells able to enhance tumor immunologic clearance.

\section{TAM Targeting Strategies: Strategies in Depleting TAMs in the Tumor Microenvironment}

Several chemotherapeutic agents also have been reported to be cytotoxic to TAMs. Bisphosphonates, used in treatment of bone metastatic cancers like breast cancer and prostate cancer (184), also have a macrophage-killing properties in addition to killing tumor cells (185). Among the most used bisphosphonates are clodronate and zoledronic acid which are administered as a single agent or in combination with others to target multiple tumorigenic components. As a drug, bisphosphonates have low bioavailability (short plasma half-life, rapid uptake within bone and rapid kidney excretion) (186) and cause severe side effects (jaw osteonecrosis, atrial fibrillation, nephrotoxicity, stress fractures and gastrointestinal lesions) (187) that limit their use and therapeutic potential. Thus, bisphosphonates nanodelivery has more advantages over conventional drug administration. 
Clodronate liposomes suppresses tumor growth and angiogenesis $(22,23)$ and zoledronic acid in the form of lipidcoated calcium zoledronate nanoparticles also depletes TAMs and attenuates tumor growth $(188,189)$.

Trabectedin is a chemotherapeutic agent used for treatment of advanced soft tissue sarcomas and recurrent ovarian cancer. Apart from having a cytotoxic effect on cancer cells, trabectedin also induces caspase 8-mediated apoptosis in monocytic phagocytes (macrophages and monocytes) via activation of TNF-related apoptosis-inducing ligand (TRAIL) receptors signalling (190). Trabectedin mediated TAM depletion and the reduction in tumor volume was observed in trabectedin-resistant murine MN/MCA1 fibrosarcoma and a xenograft model of ovarian cancer (IGROV). In addition, immunohistochemistry of tumor biopsies from cancer patients receiving trabectedin, showed a reduction of TAMs infiltration and blood vessels density compared to biopsies collected before chemotherapy initiation (190). A structurally related compound to trabectedin, lurbinectedin, also has macrophage-depleting properties. In vivo lurbinectedin administration induced TAM depletion in xenografted PDAC (191), xenograft human ovarian cancer and mouse fibrosarcoma MN/MCA1 models (192). In addition, treatment synergy in reducing tumors was found when lurbinectedin was administered in combination with gemcitabine (191). This treatment combination was also well tolerated in Phase I clinical trials in patients with advanced solid tumors (Clinical Trials.gov Identifier: NCT01970553) (193).

Overall, the above studies demonstrate that TAM depletion has tremendous potential as a novel cancer treatment as a monotherapy but also in combination with traditional therapies. However, many of these treatments, in addition to severe side effects $(186,187,194)$, will reduce the systemic macrophage populations, which are a first line of defense in the innate immune response. Considering the importance of macrophages in initiating the immune response, nanotargeting of TAMs has a potential for the development of more specific treatment with a potential low effect on the systemic macrophage population.

\section{Peptides as a Strategy to Targeted TAMs}

Nanomedicine provides a novel approach in cancer treatment. Compared to traditional chemotherapeutic treatment, specific targeting of TAMs, rather than macrophages more broadly, has the potential to increase treatment potency and reduce side effects of treatment. Several TAM specific peptides are currently being investigated and these include M2pep (195), “UNO” (196), melittin (197), RP-182 (198), IL4RPep-1 (199), T4 peptide (200), Pep-20 (201), and CRV (202) (Table 2).

Cieslewicz et al. used phage peptide display libraries $\mathrm{PhD}$ C7 and $\mathrm{PhD} 12$ to identify a peptide called M2pep that was found to bind to murine TAMs (CD45+F4/80+CD301+) in vitro and in vivo. M2pep successfully delivered a proapoptotic peptide to CT26 colon cancer cells, which led to the reduction of TAM populations and improved survival in a murine model (195). Currently M2pep is an actively researched macrophage targeting peptide that was used to develop various nanocarriers to deliver CSF-1/CSF-1R inhibitors like PLX3397 and CSF-1R-siRNA $(206,207)$, and a proapoptotic peptide (KLA peptide) (195). Several studies also have addressed the enhancement of M2pep targeting and stability. For example, M2pep(RY) with amino acid substitutions in M2pep (lysine-9 to an arginine, K9R and tryptophan-10 to a tyrosine, W10Y) and decafluorobiphenyl cyclisation through cysteines significantly enhanced binding affinity and increased serum stability $(203,204)$. Another study modified M2pep(RY) by tyrosine substitution with 3,5diiodotyrosine to develop a $\mathrm{pH}$ sensitive M2pep(RY). This peptide showed increased selectivity to IL-4 polarized (M2) macrophage over IFN- $\gamma$ and LPS polarized (M1) macrophages at $\mathrm{pH} 6$ compared to unmodified M2pep(RY) peptide in vitro (208). Despite significant research into M2pep delivery of anticancer drugs and optimization of targeting, the macrophage molecule that M2pep binds to remains unknown.

The ability of certain peptides to specifically bind to CD206+ (M2) macrophages was demonstrated for melittin, RP-182 peptide and "UNO" peptide (196-198). Melittin, a major component of honeybee (Apis mellifera L.) venom, is known for its haemolytic and cytotoxic properties. Lee et al. found that a

TABLE 2 | TAMs targeting peptides.

\begin{tabular}{|c|c|c|c|c|}
\hline Peptide & Sequence & Target & Function & References \\
\hline M2pep & YEQDPWGVKWWY-OH & Murine CD45+F4/80+CD301+TAMs & Targeting & (195) \\
\hline Cyclic M2pep(RY) & CGYEQDPWGVRYWYGC-OH & Murine CD45+F4/80+CD301+TAMs & Targeting & $(203,204)$ \\
\hline Melittin & GIGAVLKVLTTGLPALISWIKRKRQQ-NH2 & CD206 TAMs & Targeting & (197) \\
\hline "UNO" peptide & CSPGAKVRC-OH & CD206 TAMs & Targeting & $(196)$ \\
\hline RP-182 peptide & KFRKAFKRFF-OH & CD206 TAMs & $\begin{array}{l}\text { Targeting; } \\
\text { M2 macrophages apoptosis; } \\
\text { M2 macrophages repolarization towards M1 }\end{array}$ & $(198)$ \\
\hline T4 & NLLMAAS-OH & Tie2+ TAMs and endothelial cells. & $\begin{array}{l}\text { Targeting; } \\
\text { Blocks Tie2/Ang1 }\end{array}$ & $(205)$ \\
\hline IL4RPep-1 & CRKRLDRNC-OH & IL-4R+ TAMs and tumor cells. & Targeting & (199) \\
\hline Pep-20 & AWSATWSNYWRH-NH2 & CD47 & $\begin{array}{l}\text { Targeting; } \\
\text { Block CD47/SIRP } \alpha\end{array}$ & $(201)$ \\
\hline Pep-20-D12 & a w s ATWSNY w r h-NH2* & CD47 & $\begin{array}{l}\text { Targeting; } \\
\text { Block CD47/SIRP } \alpha\end{array}$ & $(201)$ \\
\hline CRV & CRVLRSGSC-OH & TAMs retinoid $X$ receptor beta & Targeting & $(202)$ \\
\hline
\end{tabular}

* Lower case letters represent D-amino acids. 
non-cytotoxic dose of melittin displayed CD206+ (M2) TAM selectivity, without inhibiting the CD86+ (M1) macrophage population or other leukocytes (197). These findings were supported by an in vivo investigation, where mice inoculated with mouse Lewis lung carcinoma and then treated with melittin and proapoptotic peptide (KLAKLA) 2 had reduced CD206+ (M2) TAM tumor infiltration, reduced tumor growth, and angiogenesis compared to control mice (197).

Peptide RP-182 was discovered by in silico screening of host defense peptides. RP-182 was found to bind to human and murine CD206+ (M2) TAMs and induce apoptosis and/or repolarization towards a proinflammatory anti-cancer CD86+ M1-like phenotype (198). The in silico modelling predicted that RP-182 may also bind to the receptors transglutaminase 2 (TGM2), RelB (a members of the NF-KB family), SIRP $\alpha$, and CD47 (209).

"UNO" peptide was identified by in vivo phage display and its GSPGAK motif (also termed as "mUNO" peptide) is found in several CD206 physiological ligands. Though the "UNO" peptide is cyclic, binding to CD206 requires peptide linearity which is enabled by the reducing conditions found in the TME. The "UNO" peptide was also able to bind to and be internalized by CD206+ expressing (M2) murine TAMs and human CD206+ (M2) macrophages $(196,210,211)$. In five independent in vivo solid tumor models, a fluorescently labelled "UNO" peptide (FAM-UNO) was found to accumulate in tumor tissues infiltrated with CD206+ (M2) TAMs, but not in nonmalignant adjacent tissues or in controlled animal tissues. In addition to intra-tumoral TAM homing, FAM-UNO has also the ability to accumulate in sentinel lymph nodes, which was observed in ex vivo AT1 tumor model (196). The ability of "UNO" peptide to deliver a therapeutic cargo was demonstrated by the increased accumulation of UNO conjugated paclitaxelloaded polymersome to CD206+ (M2) TAMs in MCF-7 breast cancer bearing mice (196). In addition, "mUNO" peptide conjugated with toll like receptor agonist TLR7/8 (resiquimod)-loaded lignin nanoparticles was shown to target CD206+ (M2) TAMs in vivo in an aggressive mice triplenegative breast cancer model (212). All these findings suggested that the "UNO" peptide is a good candidate for the development of highly specific cancer therapies and also can be used in imaging $(196,212)$.

Tyrosine-protein kinase receptor (Tie2) expressing monocytes and macrophages (TEMs) are involved in tumor angiogenesis and contribute to tumor aggressiveness. Besides TEMs, Tie2 receptor is found on endothelial cells and upon interaction with Ang1 and Ang2 this pathway has a substantial role in the formation of new vasculature $(213,214)$. Targeting tumor Tie2-mediated angiogenesis is a potential therapeutic strategy to prevent tumor access to nutrients and oxygen. The T4 peptide (NLLMAAS) was found to bind to human recombinant Tie2 receptor and was identified by a phage display peptide library testing (205). The study reported that T4 peptide blocked Tie2 interaction with Ang1 in a HUVEC cell line in vitro and inhibited angiogenesis observed in vivo in a chick chorioallantoic membrane (CAM) assay (205). T4 was explored for targeting tumor endothelial cells and TAMs to prevent breast cancer relapse in a $4 \mathrm{~T} 1$ breast cancer cell mouse model (200). For this purpose, T4 peptide was protected from proteolytic degradation by creating a dual-responsive $(\mathrm{pH}$ sensitive and enzyme cleavable) (mPEG1000-K (DEAP)-AANNLLMAAS) nanoformulation which upon exposure to the TME would expose active T4 peptide. This T4 nanoformulation was able to suppress angiogenesis, delay tumor relapse and metastasis formation in the animal model (200). Two other peptides; GA5 peptide (NSLSNASEFRAPY) and T7 (HHHRHSF) were also reported to bind the Tie2 receptor, although their binding to TEMs requires investigation $(205,215)$.

The peptide IL4RPep-1 (CRKRLDRNC) has been shown to bind to IL-4R-expressing tumor cells and M2(IL-4) polarized macrophages (199). Vadevoo et al. (199) reported that IL4RPep1 was able to deliver proapoptotic peptide (KLAKLAK)2 with paclitaxel to a $4 \mathrm{~T} 1$ breast cancer tumor and this treatment resulted in suppression of tumor growth and metastatic spread in the mouse model. Due to the high expression of IL-4 receptor in M2 macrophages, the number of M2 macrophages was significantly reduced after treatment. In addition, the reduction in Treg cells was observed together with the increase in activated cytotoxic CD8+ T cells in treated mice (199).

Wang et al. (201) discovered that Pep-20 peptide (AWSATWSNYWRH) was able to block CD47/SIRP $\alpha$ pathway by binding to CD47. An in vitro study confirmed the ability of Pep-20 to enhance macrophage phagocytic activity against a range of murine and human cancer cell lines as well as promoting macrophage-mediated development of antitumor CD8+ T cells (201). Antitumor activity of Pep-20 was also observed in a CT26 tumor mouse model, where the Pep-20 treated group showed tumor suppression and increased overall survival. In further studies Pep-20 was modified by replacing certain L-amino acid residues with their D-amino acid resides (Table 1) in an attempt to make the peptide more proteolytically stable, termed Pep-20-D12. These modifications not only improved serum stability but also increased peptide's antitumor activity against MC38 tumor in vivo (201).

Tang et al. (202) reported that cyclic CRV peptide (CRVLRSGSC) had specific binding to TAMs via retinoid $\mathrm{X}$ receptor beta, a receptor found to be expressed predominantly by TAMs $(\mathrm{CD} 11 \mathrm{~b}+, \mathrm{F} 4 / 80+, \mathrm{CD} 68+)$. The group also demonstrated peptide specific tumor homing, as fluorescently labelled (sulforhodamine 101) CRV peptide conjugated with porous silicon nanoparticles increasingly accumulated in $4 \mathrm{~T} 1$ tumor mice model comparing to nanoparticles without CRV peptide (202). CRV peptide was also used to design an immunostimulatory tandem peptide nanocomplexes conjugated with TLR9 ligand ODN1826. This nanoformulation in combination with anti-CTLA4 was tested in vivo in B16F10 tumor mice model, where the reduction in tumor volume was observed comparing to anti-CTLA4 combinations with untargeted nanocomplexes or with naked ODN1826 (216).

The above studies demonstrate the exciting potential of TAM targeting peptides to enhance cancer treatment by specific delivery of a therapeutic cargo directly to the tumor site. It is 
clear that more research is required to evaluate safety and efficiency, but some preclinical data indicate that formulations with TAM targeting peptides potentially can outperform traditional treatments $(199,207)$. The benefits of using TAM targeting peptides are tumor homing which enables specific targeting and intrinsic therapeutic activity observed in few peptides which can be used as a monotherapy or synergy with the carried cargo.

\section{Nanomaterials as an Effective TAMs Repolarization Strategy}

A primary function of macrophages is their ability to phagocytose micro- and nano-materials and this process is being exploited to alter and/or modulate macrophage phenotypes. Apart from therapeutic agents to repolarize TAMs towards M1 phenotype, some nanomaterials have been reported to have an intrinsic activity to induce phenotypical changes in macrophages. For example, Zanganeh et al. (217) demonstrated that ferumoxytol, a drug used in treatment of iron deficiency anemia, induced the upregulation of CD86 and TNF- $\alpha$ (M1 macrophage) markers in RAW264.7 macrophages co-cultured with MMTV-PyMT cancer cells. In vivo studies confirmed these findings and treatment with ferumoxytol nanoparticles (carboxy-dextran coated super paramagnetic ironoxide nanoparticles (SPIONs) (Figure 5A) induced macrophage mediated suppression of primary tumor growth in MMTV-PyMT cancer model and inhibited metastasis in a KP1-GFP-Luc cancer model (217).

Polystyrene nanoparticles functionalized with carboxyl or amino groups (Figure 5B) were also reported to impair CD163 and CD200R expression and IL-10 production in M2 macrophages without affecting the M1 population (218). In the 4T1 tumor model poly(styrene-co-maleic anhydride) (PSMA) nanoparticles conjugated with polymer poly[2-methoxy-5-(2-ethylhexyloxy)-1,4phenylenevinylene, PPV] were able to attenuate tumor growth and modulate TME by upregulation of M1 macrophage markers (CD86, CD80, iNOS, TNF-alpha) and downregulation of M2-like markers (CD206, CD163) in the TME (219).

Cationic polymers such as cationic dextran and polyethyleneimine (PEI) were shown to alter TAM phenotype via TLR4 signalling. The phenotypical changes in TAMs include the upregulation of IL-12, NOS2 and MHCII (M1-related markers) and downregulation of IL-10, Arg1 and Ym1 (M2specific markers) which were observed in vitro and in vivo in a S180 sarcoma model. Therapeutically, cationic dextran and PEI showed some anti-tumor activity in tumor bearing wild type mice compared to TLR4 knockout mice (220).

The finding that nanoparticles alone or NPs coated with cationic polymers have immunostimulatory properties that can shift the balance of macrophage phenotypes towards a M1 profile, indicates their exciting potential to enhance therapeutic strategies documented here and contribute to reducing the cancer burden after treatment, particularly when combined with targeting methods.

\section{DISCUSSION}

Macrophages are plastic and highly heterogeneous cells that have a potential to suppress or promote tumor growth. Multiple aspects of macrophage biology are being considered when developing TAM targeting strategies. Many of these strategies are already in clinical studies which gives hope of new effective treatment regimens to be used clinically and also insights into their efficacy. These clinical trials and the research into targeting TAMs has highlighted the porosity in our understanding of the macrophage subtypes present in the TME and their involvement in tumorigenesis. The increase in our understanding of the role of these subtypes in pathology will ultimately aid in the design of potent therapies. An exciting area that

\section{A SPION NP}

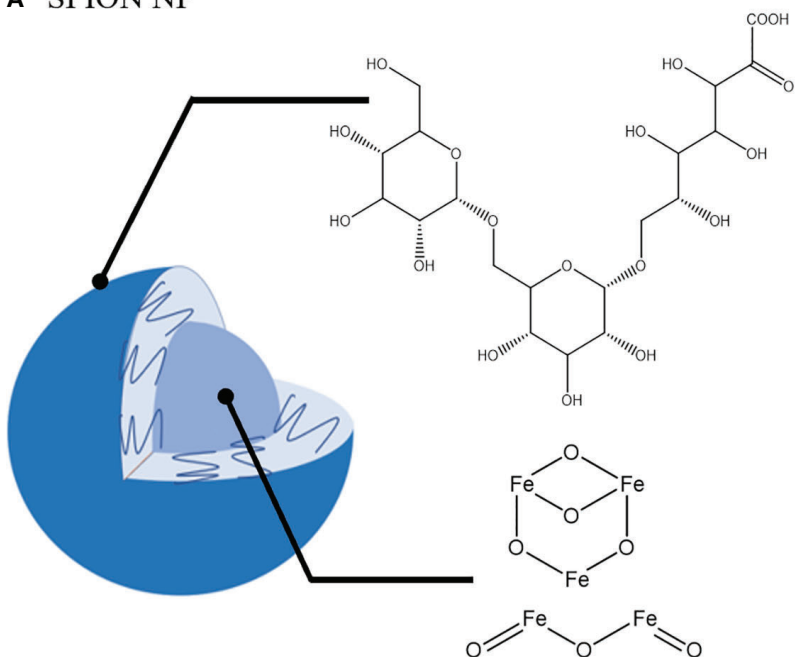

B Carboxyl- and amino-functionalized polystyrene NP

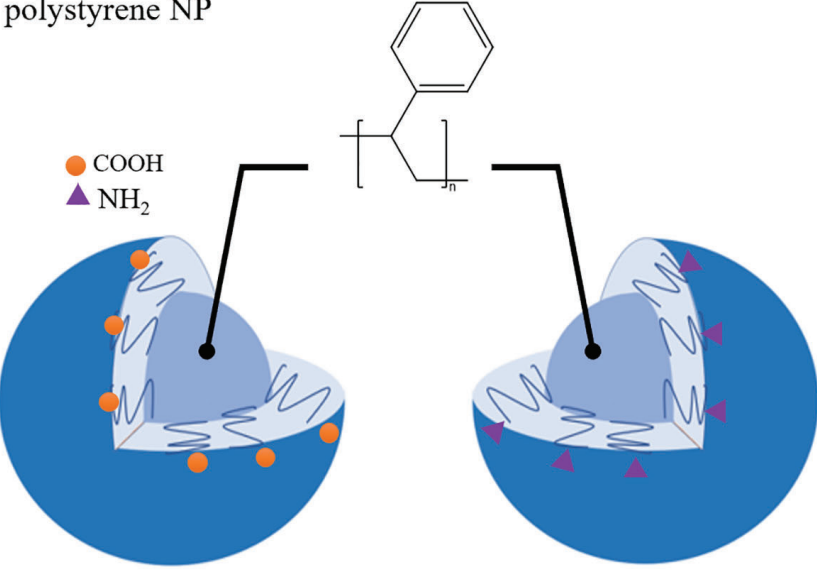

FIGURE 5 | Nanoparticles that induce TAMs phenotypic shift towards tumor-suppressive phenotype. (A). SPION nanoparticle (NP): Carboxy-dextran coating and Iron oxide core. (B). Carboxyl- and amino- functionalized NP with polystyrene core. 
is showing a high degree of potential to target TAMs is peptide and nanomaterial targeting due to their ability to modulate the TME without affecting general monocyte/macrophage populations. Indeed, these properties can be used in the development of the future cancer treatment that will be more potent and less toxic.

\section{AUTHOR CONTRIBUTIONS}

Conceptualization: TH and NO'B-S. Writing and original draft preparation: TH. Writing-review and editing: TH, NO'B-S, JH, WL, JL, and SH. Supervision of TH by NO'B-S, JH, WL, JL, and $\mathrm{SH}$. All authors have read and agreed to the published version of the manuscript. All authors contributed to the article and approved the submitted version.

\section{REFERENCES}

1. Quail DF, Joyce JA. Microenvironmental Regulation of Tumor Progression and Metastasis. Nat Med (2013) 19(11):1423-37. doi: 10.1038/nm.3394

2. Giraldo NA, Sanchez-Salas R, Peske JD, Vano Y, Becht E, Petitprez F, et al. The Clinical Role of the TME in Solid Cancer. Br J Cancer (2019) 120(1):4553. doi: 10.1038/s41416-018-0327-z

3. Belli C, Trapani D, Viale G, D'Amico P, Duso BA, Della Vigna P, et al. Targeting the Microenvironment in Solid Tumors. Cancer Treat Rev (2018) 65:22-32. doi: 10.1016/j.ctrv.2018.02.004

4. Nagarsheth N, Wicha MS, Zou W. Chemokines in the Cancer Microenvironment and Their Relevance in Cancer Immunotherapy. Nat Rev Immunol (2017) 17(9):559-72. doi: 10.1038/nri.2017.49

5. Korbecki J, Grochans S, Gutowska I, Barczak K, Baranowska-Bosiacka I. CC Chemokines in a Tumor: A Review of Pro-Cancer and Anti-Cancer Properties of Receptors CCR5, CCR6, CCR7, CCR8, CCR9, and CCR10 Ligands. Int J Mol Sci (2020) 21(20):1-34. doi: 10.3390/ijms21207619

6. Zhang M, He Y, Sun X, Li Q, Wang W, Zhao A, et al. A High M1/M2 Ratio of Tumor-Associated Macrophages Is Associated With Extended Survival in Ovarian Cancer Patients. J Ovarian Res (2014) 7:19. doi: 10.1186/17572215-7-19

7. Yin S, Huang J, Li Z, Zhang J, Luo J, Lu C, et al. The Prognostic and Clinicopathological Significance of Tumor-Associated Macrophages in Patients With Gastric Cancer: A Meta-Analysis. PLoS One (2017) 12(1): e0170042. doi: 10.1371/journal.pone.0170042

8. Cui YL, Li HK, Zhou HY, Zhang T, Li Q. Correlations of Tumor-Associated Macrophage Subtypes With Liver Metastases of Colorectal Cancer. Asian Pac J Cancer Prev (2013) 14(2):1003-7. doi: 10.7314/APJCP.2013.14.2.1003

9. Dumars C, Ngyuen JM, Gaultier A, Lanel R, Corradini N, Gouin F, et al. Dysregulation of Macrophage Polarization Is Associated With the Metastatic Process in Osteosarcoma. Oncotarget (2016) 7(48):78343-54. doi: 10.18632/oncotarget.13055

10. Mei J, Xiao Z, Guo C, Pu Q, Ma L, Liu C, et al. Prognostic Impact of TumorAssociated Macrophage Infiltration in Non-Small Cell Lung Cancer: A Systemic Review and Meta-Analysis. Oncotarget (2016) 7(23):34217-28. doi: 10.18632/oncotarget.9079

11. Dan H, Liu S, Liu J, Liu D, Yin F, Wei Z, et al. RACK1 Promotes Cancer Progression by Increasing the M2/M1 Macrophage Ratio via the NF-kappaB Pathway in Oral Squamous Cell Carcinoma. Mol Oncol (2020) 14:795-807. doi: 10.1002/1878-0261.12644

12. Mimura K, Teh JL, Okayama H, Shiraishi K, Kua LF, Koh V, et al. PD-L1 Expression Is Mainly Regulated by Interferon Gamma Associated With JAK-STAT Pathway in Gastric Cancer. Cancer Sci (2018) 109(1):43-53. doi: $10.1111 /$ cas.13424

13. Chaganty BKR, Qiu S, Gest A, Lu Y, Ivan C, Calin GA, et al. Trastuzumab Upregulates PD-L1 as a Potential Mechanism of Trastuzumab Resistance

\section{FUNDING}

TH was supported by an Australian Government Research Training Program Scholarship. The National Health and Medical Research Council (NHMRC) of Australia and Australian Research Council (ARC) are thanked for financial support over many years for the peptide chemistry and chemical biology studies reported in the authors' laboratories. NO'B-S is the recipient of NHMRC funding (APP1142472, APP1158841, APP1185426), ARC funding (DP210102781, DP160101312, LE200100163), Cancer Council Victoria funding (APP1163284) and Australian Dental Research Funding in antimicrobial materials and research is supported by the Centre for Oral Health Research in the Basic and Clinical Oral Sciences Division at The Melbourne Dental School.

Through Engagement of Immune Effector Cells and Stimulation of Ifn $\gamma$ Secretion. Cancer Lett (2018) 430:47-56. doi: 10.1016/j.canlet.2018.05.009

14. Dieterich LC, Ikenberg K, Cetintas T, Kapaklikaya K, Hutmacher C, Detmar M. Tumor-Associated Lymphatic Vessels Upregulate PDL1 to Inhibit T-Cell Activation. Front Immunol (2017) 8:66. doi: 10.3389/fimmu.2017.00066

15. Hong I-S. Stimulatory Versus Suppressive Effects of GM-CSF on Tumor Progression in Multiple Cancer Types. Exp Mol Med (2016) 48(7):e242-e. doi: $10.1038 / \mathrm{emm} .2016 .64$

16. Lee HW, Cho KJ, Park JY. Current Status and Future Direction of Immunotherapy in Hepatocellular Carcinoma: What Do the Data Suggest? Immune Netw (2020) 20(1):el1. doi: 10.4110/in.2020.20.el1

17. Wang S, Hu C, Xie F, Liu Y. Use of Programmed Death Receptor-1 and/or Programmed Death Ligand 1 Inhibitors for the Treatment of Brain Metastasis of Lung Cancer. Onco Targets Ther (2020) 13:667-83. doi: 10.2147/OTT.S235714

18. Schoenfeld AJ, Hellmann MD. Acquired Resistance to Immune Checkpoint Inhibitors. Cancer Cell (2020) 37(4):443-55. doi: 10.1016/j.ccell.2020.03.017

19. Xiang X, Wang J, Lu D, Xu X. Targeting Tumor-Associated Macrophages to Synergize Tumor Immunotherapy. Signal Transduct Target Ther (2021) 6 (1):75. doi: 10.1038/s41392-021-00484-9

20. Mantovani A, Marchesi F, Malesci A, Laghi L, Allavena P. TumourAssociated Macrophages as Treatment Targets in Oncology. Nat Rev Clin Oncol (2017) 14(7):399-416. doi: 10.1038/nrclinonc.2016.217

21. Rodell CB, Arlauckas SP, Cuccarese MF, Garris CS, Li R, Ahmed MS, et al. TLR7/8-Agonist-Loaded Nanoparticles Promote the Polarization of Tumour-Associated Macrophages to Enhance Cancer Immunotherapy. Nat BioMed Eng (2018) 2:578-88. doi: 10.1038/s41551-018-0236-8

22. Griesmann H, Drexel C, Milosevic N, Sipos B, Rosendahl J, Gress TM, et al. Pharmacological Macrophage Inhibition Decreases Metastasis Formation in a Genetic Model of Pancreatic Cancer. Gut (2017) 66(7):1278-85. doi: 10.1136/gutjnl-2015-310049

23. Piaggio F, Kondylis V, Pastorino F, Di Paolo D, Perri P, Cossu I, et al. A Novel Liposomal Clodronate Depletes Tumor-Associated Macrophages in Primary and Metastatic Melanoma: Anti-Angiogenic and Anti-Tumor Effects. J Control Release (2016) 223:165-77. doi: 10.1016/j.jconrel. 2015.12.037

24. Italiani P, Boraschi D. From Monocytes to M1/M2 Macrophages: Phenotypical vs. Functional Differentiation. Front Immunol (2014) 5:514 doi: 10.3389/fimmu.2014.00514

25. DeNardo DG, Ruffell B. Macrophages as Regulators of Tumour Immunity and Immunotherapy. Nat Rev Immunol (2019) 19(6):369-82. doi: 10.1038/ s41577-019-0127-6

26. Martinez FO, Sica A, Mantovani A, Locati M. Macrophage Activation and Polarization. Front Biosci (2008) 13:453-61. doi: 10.2741/2692

27. Jackute J, Zemaitis M, Pranys D, Sitkauskiene B, Miliauskas S, Vaitkiene S, et al. Distribution of M1 and M2 Macrophages in Tumor Islets and Stroma 
in Relation to Prognosis of Non-Small Cell Lung Cancer. BMC Immunol (2018) 19(1):3. doi: 10.1186/s12865-018-0241-4

28. Macciò A, Gramignano G, Cherchi MC, Tanca L, Melis L, Madeddu C. Role of M1-Polarized Tumor-Associated Macrophages in the Prognosis of Advanced Ovarian Cancer Patients. Sci Rep (2020) 10(1):6096. doi: 10.1038/s41598-020-63276-1

29. Yuan A, Hsiao Y-J, Chen H-Y, Chen H-W, Ho C-C, Chen Y-Y, et al. Opposite Effects of M1 and M2 Macrophage Subtypes on Lung Cancer Progression. Sci Rep (2015) 5(1):14273. doi: 10.1038/srep14273

30. Little AC, Pathanjeli P, Wu Z, Bao L, Goo L, Yates JA, et al. Abstract 4518: IL-4/IL-13 Stimulated Tumor-Associated Macrophages Enhance Breast Cancer Cell Invasion Through Rho-GTPase Signaling. Front Oncol (2019) 79: (13 Supplement):4518-. doi: 10.1158/1538-7445.AM2019-4518

31. Asai A, Tsuchimoto Y, Ohama H, Fukunishi S, Tsuda Y, Kobayashi M, et al. Host Antitumor Resistance Improved by the Macrophage Polarization in a Chimera Model of Patients With HCC. Oncoimmunology (2017) 6(4): e1299301. doi: 10.1080/2162402X.2017.1299301

32. Liu Y, Ji X, Kang N, Zhou J, Liang X, Li J, et al. Tumor Necrosis Factor $\alpha$ Inhibition Overcomes Immunosuppressive M2b Macrophage-Induced Bevacizumab Resistance in Triple-Negative Breast Cancer. Cell Death Dis (2020) 11(11):993. doi: 10.1038/s41419-020-03161-x

33. Hung C-H, Chen F-M, Lin Y-C, Tsai M-L, Wang S-L, Chen Y-C, et al. Altered Monocyte Differentiation and Macrophage Polarization Patterns in Patients With Breast Cancer. BMC Cancer (2018) 18(1):366-. doi: 10.1186/ s12885-018-4284-y

34. Cheng H, Wang Z, Fu L, Xu T. Macrophage Polarization in the Development and Progression of Ovarian Cancers: An Overview. Front Oncol (2019) 9:421-. doi: 10.3389/fonc.2019.00421

35. Fu X-L, Duan W, Su C-Y, Mao F-Y, Lv Y-P, Teng Y-S, et al. Interleukin 6 Induces M2 Macrophage Differentiation by STAT3 Activation That Correlates With Gastric Cancer Progression. Cancer Immunol Immunother (2017) 66(12):1597-608. doi: 10.1007/s00262-017-2052-5

36. Wang J, Wang Y, Chu Y, Li Z, Yu X, Huang Z, et al. Tumor-Derived Adenosine Promotes Macrophage Proliferation in Human Hepatocellular Carcinoma. J Hepatol (2020) 74:627-37. doi: 10.1016/j.jhep.2020.10.021

37. Wang X, Yang X, Tsai Y, Yang L, Chuang K-H, Keng PC, et al. IL-6 Mediates Macrophage Infiltration After Irradiation via Up-Regulation of CCL2/CCL5 in Non-Small Cell Lung Cancer. Radiat Res (2017) 187(1):50-9. doi: $10.1667 / R R 14503.1$

38. Murray PJ, Allen JE, Biswas SK, Fisher EA, Gilroy DW, Goerdt S, et al. Macrophage Activation and Polarization: Nomenclature and Experimental Guidelines. Immunity (2014) 41(1):14-20. doi: 10.1016/j.immuni.2014.06.008

39. Mosser DM, Edwards JP. Exploring the Full Spectrum of Macrophage Activation. Nat Rev Immunol (2008) 8(12):958-69. doi: 10.1038/nri2448

40. Gleissner CA, Shaked I, Little KM, Ley K. CXC Chemokine Ligand 4 Induces a Unique Transcriptome in Monocyte-Derived Macrophages. J Immunol (2010) 184(9):4810-8. doi: 10.4049/jimmunol.0901368

41. Xue J, Schmidt SV, Sander J, Draffehn A, Krebs W, Quester I, et al. Transcriptome-Based Network Analysis Reveals a Spectrum Model of Human Macrophage Activation. Immunity (2014) 40(2):274-88. doi: 10.1016/j.immuni.2014.01.006

42. Zizzo G, Cohen PL. IL-17 Stimulates Differentiation of Human AntiInflammatory Macrophages and Phagocytosis of Apoptotic Neutrophils in Response to IL-10 and Glucocorticoids. J Immunol (2013) 190(10):5237-46. doi: 10.4049/jimmunol.1203017

43. Blériot C, Chakarov S, Ginhoux F. Determinants of Resident Tissue Macrophage Identity and Function. Immunity (2020) 52(6):957-70. doi: 10.1016/j.immuni.2020.05.014

44. Zhu Y, Herndon JM, Sojka DK, Kim KW, Knolhoff BL, Zuo C, et al. TissueResident Macrophages in Pancreatic Ductal Adenocarcinoma Originate From Embryonic Hematopoiesis and Promote Tumor Progression. Immunity (2017) 47(2):323-38.e6. doi: 10.1016/j.immuni.2017.07.014

45. Wynn TA, Chawla A, Pollard JW. Macrophage Biology in Development, Homeostasis and Disease. Nature (2013) 496(7446):445-55. doi: 10.1038/ nature 12034

46. Loyher P-L, Hamon P, Laviron M, Meghraoui-Kheddar A, Goncalves E, Deng Z, et al. Macrophages of Distinct Origins Contribute to Tumor
Development in the Lung. J Exp Med (2018) 215(10):2536-53. doi: $10.1084 /$ jem.20180534

47. Chen Z, Feng X, Herting CJ, Garcia VA, Nie K, Pong WW, et al. Cellular and Molecular Identity of Tumor-Associated Macrophages in Glioblastoma. Cancer Res (2017) 77(9):2266-78. doi: 10.1158/00085472.CAN-16-2310

48. Tian Z, Hou X, Liu W, Han Z, Wei L. Macrophages and Hepatocellular Carcinoma. Cell Biosci (2019) 9:79-. doi: 10.1186/s13578-019-0342-7

49. Lee HW, Choi HJ, Ha SJ, Lee KT, Kwon YG. Recruitment of Monocytes/ Macrophages in Different Tumor Microenvironments. Biochim Biophys Acta (2013) 1835(2):170-9. doi: 10.1016/j.bbcan.2012.12.007

50. Van Overmeire E, Stijlemans B, Heymann F, Keirsse J, Morias Y, Elkrim Y, et al. M-CSF and GM-CSF Receptor Signaling Differentially Regulate Monocyte Maturation and Macrophage Polarization in the Tumor Microenvironment. Cancer Res (2016) 76(1):35-42. doi: 10.1158/00085472.CAN-15-0869

51. Lenzo JC, Turner AL, Cook AD, Vlahos R, Anderson GP, Reynolds EC, et al. Control of Macrophage Lineage Populations by CSF-1 Receptor and GMCSF in Homeostasis and Inflammation. Immunol Cell Biol (2012) 90(4):42940. doi: $10.1038 /$ icb. 2011.58

52. Hsu WC, Lee YC, Liang PI, Chang LL, Huang AM, Lin HH, et al. CSF-1 Overexpression Predicts Poor Prognosis in Upper Tract Urothelial Carcinomas. Dis Markers (2019) 2019:2724948. doi: 10.1155/2019/2724948

53. Richardsen E, Uglehus RD, Johnsen SH, Busund LT. Macrophage-Colony Stimulating Factor (CSF1) Predicts Breast Cancer Progression and Mortality. Anticancer Res (2015) 35(2):865-74.

54. Lukaszewicz-Zajac M, Mroczko B, Kozlowski M, Niklinski J, Laudanski J, Szmitkowski M. Clinical Significance of Serum Macrophage-Colony Stimulating Factor (M-CSF) in Esophageal Cancer Patients and Its Comparison With Classical Tumor Markers. Clin Chem Lab Med (2010) 48(10):1467-73. doi: 10.1515/CCLM.2010.274

55. Zhou R, Zhou Y, Chen Z. Exploration of Macrophage Colony-Stimulating Factor as a New Type of Tumor Marker. BioMed Rep (2013) 1(6):845-9. doi: $10.3892 /$ br.2013.170

56. Franzè E, Stolfi C, Troncone E, Scarozza P, Monteleone G. Role of Interleukin-34 in Cancer. Cancers (Basel) (2020) 12(1):252. doi: 10.3390/ cancers 12010252

57. Olingy CE, Dinh HQ, Hedrick CC. Monocyte Heterogeneity and Functions in Cancer. J Leukoc Biol (2019) 106(2):309-22. doi: 10.1002/JLB.4RI0818-311R

58. Wang J, Zhuang Z-G, Xu S-F, He Q, Shao Y-G, Ji M, et al. Expression of CCL2 Is Significantly Different in Five Breast Cancer Genotypes and Predicts Patient Outcome. Int J Clin Exp Med (2015) 8(9):15684-91.

59. Tsaur I, Noack A, Makarevic J, Oppermann E, Waaga-Gasser AM, Gasser M, et al. CCL2 Chemokine as a Potential Biomarker for Prostate Cancer: A Pilot Study. Cancer Res Treat (2015) 47(2):306-12. doi: 10.4143/crt.2014.015

60. Ding L, Li B, Zhao Y, Fu YF, Hu EL, Hu QG, et al. Serum CCL2 and CCL3 as Potential Biomarkers for the Diagnosis of Oral Squamous Cell Carcinoma. Tumour Biol (2014) 35(10):10539-46. doi: 10.1007/s13277-014-2306-1

61. Li X, Yao W, Yuan Y, Chen P, Li B, Li J, et al. Targeting of TumourInfiltrating Macrophages via CCL2/CCR2 Signalling as a Therapeutic Strategy Against Hepatocellular Carcinoma. Gut (2017) 66(1):157-67. doi: 10.1136/gutjnl-2015-310514

62. Grossman JG, Nywening TM, Belt BA, Panni RZ, Krasnick BA, DeNardo DG, et al. Recruitment of CCR2(+) Tumor Associated Macrophage to Sites of Liver Metastasis Confers a Poor Prognosis in Human Colorectal Cancer. Oncoimmunology (2018) 7(9):e1470729. doi: 10.1080/2162402X.2018.1470729

63. Arakaki R, Yamasaki T, Kanno T, Shibasaki N, Sakamoto H, Utsunomiya N, et al. CCL2 as a Potential Therapeutic Target for Clear Cell Renal Cell Carcinoma. Cancer Med (2016) 5(10):2920-33. doi: 10.1002/cam4.886

64. Yang H, Zhang Q, Xu M, Wang L, Chen X, Feng Y, et al. CCL2-CCR2 Axis Recruits Tumor Associated Macrophages to Induce Immune Evasion Through PD-1 Signaling in Esophageal Carcinogenesis. Mol Cancer (2020) 19(1):41. doi: 10.1186/s12943-020-01165-x

65. Chen XJ, Deng YR, Wang ZC, Wei WF, Zhou CF, Zhang YM, et al. HypoxiaInduced ZEB1 Promotes Cervical Cancer Progression via CCL8-Dependent Tumour-Associated Macrophage Recruitment. Cell Death Dis (2019) 10 (7):508. doi: 10.1038/s41419-019-1748-1 
66. Ntanasis-Stathopoulos I, Fotiou D, Terpos E. CCL3 Signaling in the Tumor Microenvironment. Adv Exp Med Biol (2020) 1231:13-21. doi: 10.1007/9783-030-36667-4_2

67. De la Fuente López M, Landskron G, Parada D, Dubois-Camacho K, Simian D, Martinez M, et al. The Relationship Between Chemokines CCL2, CCL3, and CCL4 With the Tumor Microenvironment and Tumor-Associated Macrophage Markers in Colorectal Cancer. Tumour Biol (2018) 40 (11):1010428318810059. doi: 10.1177/1010428318810059

68. Kodama T, Koma Y-I, Arai N, Kido A, Urakawa N, Nishio M, et al. CCL3CCR5 Axis Contributes to Progression of Esophageal Squamous Cell Carcinoma by Promoting Cell Migration and Invasion via Akt and ERK Pathways. Lab Invest (2020) 100(9):1140-57. doi: 10.1038/s41374-020-0441-4

69. Kitamura T, Qian BZ, Soong D, Cassetta L, Noy R, Sugano G, et al. CCL2Induced Chemokine Cascade Promotes Breast Cancer Metastasis by Enhancing Retention of Metastasis-Associated Macrophages. J Exp Med (2015) 212(7):1043-59. doi: 10.1084/jem.20141836

70. Wu Y, Li YY, Matsushima K, Baba T, Mukaida N. CCL3-CCR5 Axis Regulates Intratumoral Accumulation of Leukocytes and Fibroblasts and Promotes Angiogenesis in Murine Lung Metastasis Process. J Immunol (Baltimore Md 1950) (2008) 181(9):6384-93. doi: 10.4049/jimmunol. 181.9.6384

71. Kranjc MK, Novak M, Pestell RG, Lah TT. Cytokine CCL5 and Receptor CCR5 Axis in Glioblastoma Multiforme. Radiol Oncol (2019) 53(4):397-406. doi: 10.2478/raon-2019-0057

72. Datar I, Qiu X, Ma HZ, Yeung M, Aras S, de la Serna I, et al. RKIP Regulates CCL5 Expression to Inhibit Breast Cancer Invasion and Metastasis by Controlling Macrophage Infiltration. Oncotarget (2015) 6(36):39050-61. doi: 10.18632/oncotarget.5176

73. Walens A, DiMarco AV, Lupo R, Kroger BR, Damrauer JS, Alvarez JV. CCL5 Promotes Breast Cancer Recurrence Through Macrophage Recruitment in Residual Tumors. Elife (2019) 8:1-26. doi: 10.7554/ eLife.43653

74. Frankenberger C, Rabe D, Bainer R, Sankarasharma D, Chada K, Krausz T, et al. Metastasis Suppressors Regulate the Tumor Microenvironment by Blocking Recruitment of Prometastatic Tumor-Associated Macrophages. Cancer Res (2015) 75(19):4063-73. doi: 10.1158/0008-5472.CAN-14-3394

75. Araujo JM, Gomez AC, Aguilar A, Salgado R, Balko JM, Bravo L, et al. Effect of CCL5 Expression in the Recruitment of Immune Cells in Triple Negative Breast Cancer. Sci Rep (2018) 8(1):4899. doi: 10.1038/s41598-018-23099-7

76. Zheng J, Yang M, Shao J, Miao Y, Han J, Du J. Chemokine Receptor CX3CR1 Contributes to Macrophage Survival in Tumor Metastasis. Mol Cancer (2013) 12(1):141. doi: 10.1186/1476-4598-12-141

77. Reed JR, Stone MD, Beadnell TC, Ryu Y, Griffin TJ, Schwertfeger KL. Fibroblast Growth Factor Receptor 1 Activation in Mammary Tumor Cells Promotes Macrophage Recruitment in a CX3CL1-Dependent Manner. PLoS One (2012) 7(9):e45877. doi: 10.1371/journal.pone.0045877

78. Schmall A, Al-Tamari HM, Herold S, Kampschulte M, Weigert A, Wietelmann A, et al. Macrophage and Cancer Cell Cross-Talk via CCR2 and CX3CR1 Is a Fundamental Mechanism Driving Lung Cancer. Am J Respir Crit Care Med (2015) 191(4):437-47. doi: 10.1164/rccm.201406-1137OC

79. Feng X, Szulzewsky F, Yerevanian A, Chen Z, Heinzmann D, Rasmussen $\mathrm{RD}$, et al. Loss of CX3CR1 Increases Accumulation of Inflammatory Monocytes and Promotes Gliomagenesis. Oncotarget (2015) 6(17):1507794. doi: 10.18632/oncotarget.3730

80. Henze A-T, Mazzone M. The Impact of Hypoxia on Tumor-Associated Macrophages. J Clin Investig (2016) 126(10):3672-9. doi: 10.1172/ JCI84427

81. Balamurugan K. HIF-1 at the Crossroads of Hypoxia, Inflammation, and Cancer. Int J Cancer (2016) 138(5):1058-66. doi: 10.1002/ijc.29519

82. Albadari N, Deng S, Li W. The Transcriptional Factors HIF-1 and HIF-2 and Their Novel Inhibitors in Cancer Therapy. Expert Opin Drug Discov (2019) 14(7):667-82. doi: 10.1080/17460441.2019.1613370

83. Sica A, Mantovani A. Macrophage Plasticity and Polarization: In Vivo Veritas. J Clin Investig (2012) 122(3):787-95. doi: 10.1172/JCI59643

84. Reinartz S, Schumann T, Finkernagel F, Wortmann A, Jansen JM, Meissner W, et al. Mixed-Polarization Phenotype of Ascites-Associated Macrophages in Human Ovarian Carcinoma: Correlation of CD163 Expression, Cytokine
Levels and Early Relapse. Int J Cancer (2014) 134(1):32-42. doi: 10.1002/ ijc. 28335

85. Qian BZ, Pollard JW. Macrophage Diversity Enhances Tumor Progression and Metastasis. Cell (2010) 141(1):39-51. doi: 10.1016/j.cell.2010.03.014

86. Sidibe A, Ropraz P, Jemelin S, Emre Y, Poittevin M, Pocard M, et al. Angiogenic Factor-Driven Inflammation Promotes Extravasation of Human Proangiogenic Monocytes to Tumours. Nat Commun (2018) 9(1):355. doi: 10.1038/s41467-017-02610-0

87. Riabov V, Gudima A, Wang N, Mickley A, Orekhov A, Kzhyshkowska J. Role of Tumor Associated Macrophages in Tumor Angiogenesis and Lymphangiogenesis. Front Physiol (2014) 5:75. doi: 10.3389/fphys. 2014.00075

88. Poltavets V, Kochetkova M, Pitson SM, Samuel MS. The Role of the Extracellular Matrix and Its Molecular and Cellular Regulators in Cancer Cell Plasticity. Front Oncol (2018) 8:431-. doi: 10.3389/fonc.2018.00431

89. Tang CH, Tsai CC. CCL2 Increases MMP-9 Expression and Cell Motility in Human Chondrosarcoma Cells via the Ras/Raf/MEK/ERK/NF-kappaB Signaling Pathway. Biochem Pharmacol (2012) 83(3):335-44. doi: 10.1016/ j.bcp.2011.11.013

90. Larionova I, Cherdyntseva N, Liu T, Patysheva M, Rakina M, Kzhyshkowska J. Interaction of Tumor-Associated Macrophages and Cancer Chemotherapy. Oncoimmunology (2019) 8(7):1596004. doi: 10.1080/ 2162402X.2019.1596004

91. Ye L, Zhang T, Kang Z, Guo G, Sun Y, Lin K, et al. Tumor-Infiltrating Immune Cells Act as a Marker for Prognosis in Colorectal Cancer. Front Immunol (2019) 10:2368. doi: 10.3389/fimmu.2019.02368

92. Ohaegbulam KC, Assal A, Lazar-Molnar E, Yao Y, Zang X. Human Cancer Immunotherapy With Antibodies to the PD-1 and PD-L1 Pathway. Trends Mol Med (2015) 21(1):24-33. doi: 10.1016/j.molmed.2014.10.009

93. Kryczek I, Zou L, Rodriguez P, Zhu G, Wei S, Mottram P, et al. B7-H4 Expression Identifies a Novel Suppressive Macrophage Population in Human Ovarian Carcinoma. J Exp Med (2006) 203(4):871-81. doi: 10.1084/jem.20050930

94. Sabat R, Grütz G, Warszawska K, Kirsch S, Witte E, Wolk K, et al. Biology of Interleukin-10. Cytokine Growth Factor Rev (2010) 21(5):331-44. doi: 10.1016/j.cytogfr.2010.09.002

95. Batlle E, Massagué J. Transforming Growth Factor- $\beta$ Signaling in Immunity and Cancer. Immunity (2019) 50(4):924-40. doi: 10.1016/j.immuni. 2019.03.024

96. Zhang X, Zeng Y, Qu Q, Zhu J, Liu Z, Ning W, et al. PD-L1 Induced by IFN$\gamma$ From Tumor-Associated Macrophages via the JAK/STAT3 and PI3K/AKT Signaling Pathways Promoted Progression of Lung Cancer. Int J Clin Oncol (2017) 22(6):1026-33. doi: 10.1007/s10147-017-1161-7

97. Li X, Liu R, Su X, Pan Y, Han X, Shao C, et al. Harnessing Tumor-Associated Macrophages as Aids for Cancer Immunotherapy. Mol Cancer (2019) 18 (1):177. doi: 10.1186/s12943-019-1102-3

98. Lewis JS, Landers RJ, Underwood JC, Harris AL, Lewis CE. Expression of Vascular Endothelial Growth Factor by Macrophages Is Up-Regulated in Poorly Vascularized Areas of Breast Carcinomas. J Pathol (2000) 192 (2):150-8. doi: 10.1002/1096-9896(2000)9999:9999<::AID PATH687>3.0.CO;2-G

99. Li X, Bu W, Meng L, Liu X, Wang S, Jiang L, et al. CXCL12/CXCR4 Pathway Orchestrates CSC-Like Properties by CAF Recruited Tumor Associated Macrophage in OSCC. Exp Cell Res (2019) 378(2):131-8. doi: 10.1016/ j.yexcr.2019.03.013

100. Raschioni C, Bottai G, Sagona A, Errico V, Testori A, Gatzemeier W, et al. CXCR4/CXCL12 Signaling and Protumor Macrophages in Primary Tumors and Sentinel Lymph Nodes Are Involved in Luminal B Breast Cancer Progression. Dis Markers (2018) 2018:5018671. doi: 10.1155/2018/5018671

101. Yu X, Wang D, Wang X, Sun S, Zhang Y, Wang S, et al. CXCL12/CXCR4 Promotes Inflammation-Driven Colorectal Cancer Progression Through Activation of RhoA Signaling by Sponging miR-133a-3p. J Exp Clin Cancer Res (2019) 38(1):32. doi: 10.1186/s13046-018-1014-X

102. Liao T, Chen W, Sun J, Zhang Y, Hu X, Yang S, et al. CXCR4 Accelerates Osteoclastogenesis Induced by Non-Small Cell Lung Carcinoma Cells Through Self-Potentiation and VCAM1 Secretion. Cell Physiol Biochem (2018) 50(3):1084-99. doi: 10.1159/000494533 
103. Ehling J, Tacke F. Role of Chemokine Pathways in Hepatobiliary Cancer. Cancer Lett (2016) 379(2):173-83. doi: 10.1016/j.canlet.2015.06.017

104. Arwert EN, Harney AS, Entenberg D, Wang Y, Sahai E, Pollard JW, et al. A Unidirectional Transition From Migratory to Perivascular Macrophage Is Required for Tumor Cell Intravasation. Cell Rep (2018) 23(5):1239-48. doi: 10.1016/j.celrep.2018.04.007

105. Ye H, Zhou Q, Zheng S, Li G, Lin Q, Wei L, et al. Tumor-Associated Macrophages Promote Progression and the Warburg Effect via CCL18/NF$\mathrm{Kb} / \mathrm{VCAM}-1$ Pathway in Pancreatic Ductal Adenocarcinoma. Cell Death Dis (2018) 9(5):453. doi: 10.1038/s41419-018-0486-0

106. She L, Qin Y, Wang J, Liu C, Zhu G, Li G, et al. Tumor-Associated Macrophages Derived CCL18 Promotes Metastasis in Squamous Cell Carcinoma of the Head and Neck. Cancer Cell Int (2018) 18(1):120. doi: 10.1186/s12935-018-0620-1

107. Su Y, Zhou Y, Sun Y-J, Wang Y-L, Yin J-Y, Huang Y-J, et al. MacrophageDerived CCL18 Promotes Osteosarcoma Proliferation and Migration by Upregulating the Expression of UCA1. J Mol Med (2019) 97(1):49-61. doi: 10.1007/s00109-018-1711-0

108. Zhou Z, Peng Y, Wu X, Meng S, Yu W, Zhao J, et al. CCL18 Secreted From M2 Macrophages Promotes Migration and Invasion via the PI3K/Akt Pathway in Gallbladder Cancer. Cell Oncol (Dordr) (2019) 42(1):81-92. doi: 10.1007/s13402-018-0410-8

109. Lin Z, Li W, Zhang H, Wu W, Peng Y, Zeng Y, et al. CCL18/PITPNM3 Enhances Migration, Invasion, and EMT Through the NF-kb Signaling Pathway in Hepatocellular Carcinoma. Tumour Biol (2016) 37(3):3461-8. doi: 10.1007/s13277-015-4172-x

110. Shi L, Zhang B, Sun X, Zhang X, Lv S, Li H, et al. CC Chemokine Ligand 18 (CCL18) Promotes Migration and Invasion of Lung Cancer Cells by Binding to Nir1 Through Nir1-ELMO1/DOC180 Signaling Pathway. Mol Carcinog (2016) 55(12):2051-62. doi: 10.1002/mc.22450

111. Hou X, Zhang Y, Qiao H. CCL18 Promotes the Invasion and Migration of Gastric Cancer Cells via ERK1/2/NF-kappaB Signaling Pathway. Tumour Biol (2016) 37(1):641-51. doi: 10.1007/s13277-015-3825-0

112. Chenivesse C, Tsicopoulos A. CCL18 - Beyond Chemotaxis. Cytokine (2018) 109:52-6. doi: 10.1016/j.cyto.2018.01.023

113. Lin Y, Xu J, Lan H. Tumor-Associated Macrophages in Tumor Metastasis: Biological Roles and Clinical Therapeutic Applications. J Hematol Oncol (2019) 12(1):76. doi: 10.1186/s13045-019-0760-3

114. Liu G, Yin L, Ouyang X, Zeng K, Xiao Y, Li Y. M2 Macrophages Promote HCC Cells Invasion and Migration via miR-149-5p/MMP9 Signaling. $J$ Cancer (2020) 11(5):1277-87. doi: 10.7150/jca.35444

115. Xu J, Yu Y, He X, Niu N, Li X, Zhang R, et al. Tumor-Associated Macrophages Induce Invasion and Poor Prognosis in Human Gastric Cancer in a Cyclooxygenase-2/MMP9-Dependent Manner. Am J Transl Res (2019) 11(9):6040-54.

116. Tian Y, Guo Y, Zhu P, Zhang D, Liu S, Tang M, et al. TRIM59 Loss in M2 Macrophages Promotes Melanoma Migration and Invasion by Upregulating MMP-9 and Madcam1. Aging (2019) 11(19):8623-41. doi: 10.18632/ aging. 102351

117. Vinnakota K, Zhang Y, Selvanesan BC, Topi G, Salim T, Sand-Dejmek J, et al. M2-Like Macrophages Induce Colon Cancer Cell Invasion via Matrix Metalloproteinases. J Cell Physiol (2017) 232(12):3468-80. doi: 10.1002/ jcp. 25808

118. Pelekanou V, Villarroel-Espindola F, Schalper KA, Pusztai L, Rimm DL. CD68, CD163, and Matrix Metalloproteinase 9 (MMP-9) Co-Localization in Breast Tumor Microenvironment Predicts Survival Differently in ERPositive and -Negative Cancers. Breast Cancer Res (2018) 20(1):154. doi: 10.1186/s13058-018-1076-x

119. Balermpas P, Rodel F, Liberz R, Oppermann J, Wagenblast J, Ghanaati S, et al. Head and Neck Cancer Relapse After Chemoradiotherapy Correlates With CD163+ Macrophages in Primary Tumour and CD11b+ Myeloid Cells in Recurrences. Br J Cancer (2014) 111(8):1509-18. doi: 10.1038/bjc. 2014.446

120. Stafford JH, Hirai T, Deng L, Chernikova SB, Urata K, West BL, et al. Colony Stimulating Factor 1 Receptor Inhibition Delays Recurrence of Glioblastoma After Radiation by Altering Myeloid Cell Recruitment and Polarization. Neuro-oncology (2016) 18(6):797-806. doi: 10.1093/neuonc/nov272
121. Yang M, Li Z, Ren M, Li S, Zhang L, Zhang X, et al. Stromal Infiltration of Tumor-Associated Macrophages Conferring Poor Prognosis of Patients With Basal-Like Breast Carcinoma. J Cancer (2018) 9(13):2308-16. doi: 10.7150/jca.25155

122. Yang C, Wei C, Wang S, Shi D, Zhang C, Lin X, et al. Elevated CD163 $(+) / C D 68(+)$ Ratio at Tumor Invasive Front Is Closely Associated With Aggressive Phenotype and Poor Prognosis in Colorectal Cancer. Int J Biol Sci (2019) 15(5):984-98. doi: 10.7150/ijbs.29836

123. Sugimura K, Miyata H, Tanaka K, Takahashi T, Kurokawa Y, Yamasaki M, et al. High Infiltration of Tumor-Associated Macrophages Is Associated With a Poor Response to Chemotherapy and Poor Prognosis of Patients Undergoing Neoadjuvant Chemotherapy for Esophageal Cancer. J Surg Oncol (2015) 111(6):752-9. doi: 10.1002/jso.23881

124. Pichler R, Fritz J, Zavadil C, Schafer G, Culig Z, Brunner A. TumorInfiltrating Immune Cell Subpopulations Influence the Oncologic Outcome After Intravesical Bacillus Calmette-Guerin Therapy in Bladder Cancer. Oncotarget (2016) 7(26):39916-30. doi: 10.18632/oncotarget.9537

125. Lima L, Oliveira D, Tavares A, Amaro T, Cruz R, Oliveira MJ, et al. The Predominance of M2-Polarized Macrophages in the Stroma of Low-Hypoxic Bladder Tumors Is Associated With BCG Immunotherapy Failure. Urol Oncol (2014) 32(4):449-57. doi: 10.1016/j.urolonc.2013.10.012

126. Fu XT, Song K, Zhou J, Shi YH, Liu WR, Shi GM, et al. Tumor-Associated Macrophages Modulate Resistance to Oxaliplatin via Inducing Autophagy in Hepatocellular Carcinoma. Cancer Cell Int (2019) 19:71. doi: 10.1186/ s12935-019-0771-8

127. Shree T, Olson OC, Elie BT, Kester JC, Garfall AL, Simpson K, et al. Macrophages and Cathepsin Proteases Blunt Chemotherapeutic Response in Breast Cancer. Genes Dev (2011) 25(23):2465-79. doi: 10.1101/ gad.180331.111

128. Zhu X, Shen H, Yin X, Yang M, Wei H, Chen Q, et al. Macrophages Derived Exosomes Deliver miR-223 to Epithelial Ovarian Cancer Cells to Elicit a Chemoresistant Phenotype. J Exp Clin Cancer Res (2019) 38(1):81. doi: 10.1186/s13046-019-1095-1

129. Kalbasi A, Komar C, Tooker GM, Liu M, Lee JW, Gladney WL, et al. TumorDerived CCL2 Mediates Resistance to Radiotherapy in Pancreatic Ductal Adenocarcinoma. Clin Cancer Res (2017) 23(1):137-48. doi: 10.1158/10780432.CCR-16-0870

130. Hattermann K, Sebens S, Helm O, Schmitt AD, Mentlein R, Mehdorn HM, et al. Chemokine Expression Profile of Freshly Isolated Human Glioblastoma-Associated Macrophages/Microglia. Oncol Rep (2014) 32 (1):270-6. doi: 10.3892/or.2014.3214

131. Walker ND, Elias M, Guiro K, Bhatia R, Greco SJ, Bryan M, et al. Exosomes From Differentially Activated Macrophages Influence Dormancy or Resurgence of Breast Cancer Cells Within Bone Marrow Stroma. Cell Death Dis (2019) 10(2):59. doi: 10.1038/s41419-019-1304-z

132. Sousa S, Brion R, Lintunen M, Kronqvist P, Sandholm J, Monkkonen J, et al. Human Breast Cancer Cells Educate Macrophages Toward the M2 Activation Status. Breast Cancer Res (2015) 17:101. doi: 10.1186/s13058015-0621-0

133. Boyle ST, Faulkner JW, McColl SR, Kochetkova M. The Chemokine Receptor CCR6 Facilitates the Onset of Mammary Neoplasia in the MMTV-PyMT Mouse Model via Recruitment of Tumor-Promoting Macrophages. Mol Cancer (2015) 14(1):115. doi: 10.1186/s12943-0150394-1

134. Cassetta L, Fragkogianni S, Sims AH, Swierczak A, Forrester LM, Zhang H, et al. Human Tumor-Associated Macrophage and Monocyte Transcriptional Landscapes Reveal Cancer-Specific Reprogramming, Biomarkers, and Therapeutic Targets. Cancer Cell (2019) 35(4):588-602.e10. doi: 10.1016/ j.ccell.2019.02.009

135. Bai J, Adriani G, Dang TM, Tu TY, Penny HX, Wong SC, et al. ContactDependent Carcinoma Aggregate Dispersion by M2a Macrophages via ICAM-1 and Beta2 Integrin Interactions. Oncotarget (2015) 6(28):25295307. doi: $10.18632 /$ oncotarget. 4716

136. Dong P, Ma L, Liu L, Zhao G, Zhang S, Dong L, et al. CD86(+)/CD206(+), Diametrically Polarized Tumor-Associated Macrophages, Predict Hepatocellular Carcinoma Patient Prognosis. Int J Mol Sci (2016) 17 (3):320. doi: 10.3390/ijms17030320 
137. Ambade A, Satishchandran A, Saha B, Gyongyosi B, Lowe P, Kodys K, et al. Hepatocellular Carcinoma Is Accelerated by NASH Involving M2 Macrophage Polarization Mediated by Hif-1alphainduced IL-10. Oncoimmunology (2016) 5 (10):e1221557. doi: 10.1080/2162402x.2016.1221557

138. Bagul N, Roy S, Ganjre A, Kathariya R, Meher A, Singh P. Quantitative Assessment of Tumor Associated Macrophages in Head and Neck Squamous Cell Carcinoma Using CD68 Marker: An Immunohistochemical Study. J Clin Diagn Res (2016) 10(4):Zc81-4. doi: 10.7860/JCDR/2016/13924.7670

139. He KF, Zhang L, Huang CF, Ma SR, Wang YF, Wang WM, et al. CD163+ Tumor-Associated Macrophages Correlated With Poor Prognosis and Cancer Stem Cells in Oral Squamous Cell Carcinoma. BioMed Res Int (2014) 2014:838632. doi: 10.1155/2014/838632

140. Haque A, Moriyama M, Kubota K, Ishiguro N, Sakamoto M, Chinju A, et al. CD206(+) Tumor-Associated Macrophages Promote Proliferation and Invasion in Oral Squamous Cell Carcinoma via EGF Production. Sci Rep (2019) 9(1):14611. doi: 10.1038/s41598-019-51149-1

141. Kowal J, Kornete M, Joyce JA. Re-Education of Macrophages as a Therapeutic Strategy in Cancer. Immunotherapy (2019) 11(8):677-89. doi: 10.2217/imt-2018-0156

142. Peyraud F, Cousin S, Italiano A. CSF-1R Inhibitor Development: Current Clinical Status. Curr Oncol Rep (2017) 19(11):70. doi: 10.1007/s11912-017-0634-1

143. Lamb YN. Pexidartinib: First Approval. Drugs (2019) 79(16):1805-12. doi: 10.1007/s40265-019-01210-0

144. Wesolowski R, Sharma N, Reebel L, Rodal MB, Peck A, West BL, et al. Phase Ib Study of the Combination of Pexidartinib (PLX3397), a CSF-1R Inhibitor, and Paclitaxel in Patients With Advanced Solid Tumors. Ther Adv Med Oncol (2019) 11:1758835919854238. doi: 10.1177/1758835919854238

145. Zhou Y, Shan S, Li ZB, Xin LJ, Pan DS, Yang QJ, et al. CS2164, a Novel MultiTarget Inhibitor Against Tumor Angiogenesis, Mitosis and Chronic Inflammation With Anti-Tumor Potency. Cancer Sci (2017) 108(3):46977. doi: 10.1111/cas.13141

146. Sun Y, Yang L, Hao X, Liu Y, Zhang J, Ning Z, et al. Phase I Dose-Escalation Study of Chiauranib, a Novel Angiogenic, Mitotic, and Chronic Inflammation Inhibitor, in Patients With Advanced Solid Tumors. J Hematol Oncol (2019) 12(1):9. doi: 10.1186/s13045-018-0695-0

147. Ries CH, Cannarile MA, Hoves S, Benz J, Wartha K, Runza V, et al. Targeting Tumor-Associated Macrophages With Anti-CSF-1R Antibody Reveals a Strategy for Cancer Therapy. Cancer Cell (2014) 25(6):846-59. doi: 10.1016/j.ccr.2014.05.016

148. Weiss SA, Djureinovic D, Jessel S, Krykbaeva I, Zhang L, Jilaveanu L, et al. A Phase I Study of APX005M and Cabiralizumab With or Without Nivolumab in Patients With Melanoma, Kidney Cancer, or Non-Small Cell Lung Cancer Resistant to Anti-PD-1/PD-L1. Clin Cancer Res (2021) 27:4757-67. doi: 10.1158/1078-0432.CCR-21-0903

149. Lu X, Meng T. Depletion of Tumor-Associated Macrophages Enhances the Anti-Tumor Effect of Docetaxel in a Murine Epithelial Ovarian Cancer. Immunobiology (2019) 224(3):355-61. doi: 10.1016/j.imbio.2019.03.002

150. Guan W, Hu J, Yang L, Tan P, Tang Z, West BL, et al. Inhibition of TAMs Improves the Response to Docetaxel in Castration-Resistant Prostate Cancer. Endocr Relat Cancer (2019) 26(1):131-40. doi: 10.1530/ERC-18-0284

151. Halbrook CJ, Pontious C, Kovalenko I, Lapienyte L, Dreyer S, Lee HJ, et al. Macrophage-Released Pyrimidines Inhibit Gemcitabine Therapy in Pancreatic Cancer. Cell Metab (2019) 29(6):1390-9.e6. doi: 10.1016/ j.cmet.2019.02.001

152. Sandhu SK, Papadopoulos K, Fong PC, Patnaik A, Messiou C, Olmos D, et al. A First-in-Human, First-in-Class, Phase I Study of Carlumab (CNTO 888), a Human Monoclonal Antibody Against CC-Chemokine Ligand 2 in Patients With Solid Tumors. Cancer Chemother Pharmacol (2013) 71(4):1041-50. doi: 10.1007/s00280-013-2099-8

153. Pienta KJ, Machiels JP, Schrijvers D, Alekseev B, Shkolnik M, Crabb SJ, et al. Phase 2 Study of Carlumab (CNTO 888), a Human Monoclonal Antibody Against CCChemokine Ligand 2 (CCL2), in Metastatic Castration-Resistant Prostate Cancer. Invest New Drugs (2013) 31(3):760-8. doi: 10.1007/s10637-012-9869-8

154. Nywening TM, Wang-Gillam A, Sanford DE, Belt BA, Panni RZ, Cusworth $\mathrm{BM}$, et al. Targeting Tumour-Associated Macrophages With CCR2 Inhibition in Combination With FOLFIRINOX in Patients With Borderline Resectable and Locally Advanced Pancreatic Cancer: A Single-
Centre, Open-Label, Dose-Finding, Non-Randomised, Phase 1b Trial. Lancet Oncol (2016) 17(5):651-62. doi: 10.1016/S1470-2045(16)00078-4

155. Noel M, O'Reilly EM, Wolpin BM, Ryan DP, Bullock AJ, Britten CD, et al. Phase 1b Study of a Small Molecule Antagonist of Human Chemokine (C-C Motif) Receptor 2 (PF-04136309) in Combination With Nab-Paclitaxel/ Gemcitabine in First-Line Treatment of Metastatic Pancreatic Ductal Adenocarcinoma. Invest New Drugs (2019) 38:800-11. doi: 10.1007/ s10637-019-00830-3

156. Aldinucci D, Casagrande N. Inhibition of the CCL5/CCR5 Axis Against the Progression of Gastric Cancer. Int J Mol Sci (2018) 19(5):1-16. doi: 10.3390/ ijms 19051477

157. Aldinucci D, Borghese C, Casagrande N. The CCL5/CCR5 Axis in Cancer Progression. Cancers (Basel) (2020) 12(7):1-30. doi: 10.3390/ cancers 12071765

158. Halama N, Zoernig I, Berthel A, Kahlert C, Klupp F, Suarez-Carmona M, et al. Tumoral Immune Cell Exploitation in Colorectal Cancer Metastases Can Be Targeted Effectively by Anti-CCR5 Therapy in Cancer Patients. Cancer Cell (2016) 29(4):587-601. doi: 10.1016/j.ccell.2016.03.005

159. Pestell RG, Cristofanilli M, Rui H, Jiao X, Wang M. Abstract PD4-04: Leronlimab, a Humanized Monoclonal Antibody to CCR5, Restrains Breast Cancer Metastasis and Enhances Cell Death Induced by DNA Damaging Chemotherapies. Cancer Res (2020) 80(4 Supplement):PD404-PD4-. doi: 10.1158/1538-7445.SABCS19-PD4-04

160. Tabuchi H, Katsurabara T, Mori M, Aoyama M, Obara T, Yasuda N, et al. Pharmacokinetics, Pharmacodynamics, and Safety of E6011, a Novel Humanized Antifractalkine (CX3CL1) Monoclonal Antibody: A Randomized, Double-Blind, Placebo-Controlled Single-AscendingDose Study. J Clin Pharmacol (2019) 59(5):688-701. doi: 10.1002/ jcph.1361

161. Poupel L, Boissonnas A, Hermand P, Dorgham K, Guyon E, Auvynet C, et al. Pharmacological Inhibition of the Chemokine Receptor, CX3CR1, Reduces Atherosclerosis in Mice. Arterioscler Thromb Vasc Biol (2013) 33(10):2297305. doi: 10.1161/ATVBAHA.112.300930

162. Shen F, Zhang Y, Jernigan DL, Feng X, Yan J, Garcia FU, et al. Novel SmallMolecule CX3CR1 Antagonist Impairs Metastatic Seeding and Colonization of Breast Cancer Cells. Mol Cancer Res (2016) 14(6):518-27. doi: 10.1158/ 1541-7786.MCR-16-0013

163. Lehto J, Huguet Ninou A, Chioureas D, Jonkers J, Gustafsson NMS. Targeting CX3CR1 Suppresses the Fanconi Anemia DNA Repair Pathway and Synergizes With Platinum. Cancers (Basel) (2021) 13(6):1442. doi: $10.3390 /$ cancers 13061442

164. Wanderley CW, Colon DF, Luiz JPM, Oliveira FF, Viacava PR, Leite CA, et al. Paclitaxel Reduces Tumor Growth by Reprogramming TumorAssociated Macrophages to an M1 Profile in a TLR4-Dependent Manner. Cancer Res (2018) 78(20):5891-900. doi: 10.1158/00085472.CAN-17-3480

165. Sprinzl MF, Puschnik A, Schlitter AM, Schad A, Ackermann K, Esposito I, et al. Sorafenib Inhibits Macrophage-Induced Growth of Hepatoma Cells by Interference With Insulin-Like Growth Factor-1 Secretion. J Hepatol (2015) 62(4):863-70. doi: 10.1016/j.jhep.2014.11.011

166. Feng M, Jiang W, Kim BYS, Zhang CC, Fu Y-X, Weissman IL. Phagocytosis Checkpoints as New Targets for Cancer Immunotherapy. Nat Rev Cancer (2019) 19(10):568-86. doi: 10.1038/s41568-019-0183-Z

167. Chao MP, Weissman IL, Majeti R. The CD47-SIRPalpha Pathway in Cancer Immune Evasion and Potential Therapeutic Implications. Curr Opin Immunol (2012) 24(2):225-32. doi: 10.1016/j.coi.2012.01.010

168. Zhang W, Huang Q, Xiao W, Zhao Y, Pi J, Xu H, et al. Advances in AntiTumor Treatments Targeting the CD47/SIRP $\alpha$ Axis. Front Immunol (2020) 11(18). doi: 10.3389/fimmu.2020.00018

169. Sikic BI, Lakhani N, Patnaik A, Shah SA, Chandana SR, Rasco D, et al. FirstIn-Human, First-In-Class Phase I Trial of the Anti-CD47 Antibody Hu5F9G4 in Patients With Advanced Cancers. J Clin Oncol (2019) 37(12):946-53. doi: 10.1200/JCO.18.02018

170. Patnaik A, Spreafico A, Paterson AM, Peluso M, Chung J-K, Bowers B, et al. Results of a First-in-Human Phase I Study of SRF231, a Fully Human, HighAffinity Anti-CD47 Antibody. J Clin Oncol (2020) 38(15_suppl):3064-. doi: 10.1200/JCO.2020.38.15_suppl.3064 
171. Zhang H, Li F, Yang Y, Chen J, Hu X. SIRP/CD47 Signaling in Neurological Disorders. Brain Res (2015) 1623:74-80. doi: 10.1016/j.brainres.2015.03.012

172. Piechutta M, Berghoff AS. New Emerging Targets in Cancer Immunotherapy: The Role of Cluster of Differentiation 40 (Cd40/Tnfr5). ESMO Open (2019) 4(Suppl 3):e000510-e. doi: 10.1136/esmoopen-2019000510

173. Beatty GL, Torigian DA, Chiorean EG, Saboury B, Brothers A, Alavi A, et al. A Phase I Study of an Agonist CD40 Monoclonal Antibody (CP-870,893) in Combination With Gemcitabine in Patients With Advanced Pancreatic Ductal Adenocarcinoma. Clin Cancer Res (2013) 19(22):6286-95. doi: 10.1158/1078-0432.CCR-13-1320

174. Vonderheide RH, Burg JM, Mick R, Trosko JA, Li D, Shaik MN, et al. Phase I Study of the CD40 Agonist Antibody CP-870,893 Combined With Carboplatin and Paclitaxel in Patients With Advanced Solid Tumors. Oncoimmunology (2013) 2(1):e23033. doi: 10.4161/onci.23033

175. Johnson P, Challis R, Chowdhury F, Gao Y, Harvey M, Geldart T, et al. Clinical and Biological Effects of an Agonist Anti-CD40 Antibody: A Cancer Research UK Phase I Study. Clin Cancer Res (2015) 21(6):1321-8. doi: 10.1158/1078-0432.CCR-14-2355

176. Pyonteck SM, Akkari L, Schuhmacher AJ, Bowman RL, Sevenich L, Quail DF, et al. CSF-1R Inhibition Alters Macrophage Polarization and Blocks Glioma Progression. Nat Med (2013) 19(10):1264-72. doi: 10.1038/nm.3337

177. Yan D, Kowal J, Akkari L, Schuhmacher AJ, Huse JT, West BL, et al. Inhibition of Colony Stimulating Factor-1 Receptor Abrogates Microenvironment-Mediated Therapeutic Resistance in Gliomas. Oncogene (2017) 36(43):6049-58. doi: 10.1038/onc.2017.261

178. Ao JY, Zhu XD, Chai ZT, Cai H, Zhang YY, Zhang KZ, et al. ColonyStimulating Factor 1 Receptor Blockade Inhibits Tumor Growth by Altering the Polarization of Tumor-Associated Macrophages in Hepatocellular Carcinoma. Mol Cancer Ther (2017) 16(8):1544-54. doi: 10.1158/15357163.MCT-16-0866

179. La Fleur L, Boura VF, Alexeyenko A, Berglund A, Ponten V, Mattsson JSM, et al. Expression of Scavenger Receptor MARCO Defines a Targetable Tumor-Associated Macrophage Subset in Non-Small Cell Lung Cancer. Int J Cancer (2018) 143(7):1741-52. doi: 10.1002/ijc.31545

180. Zheng W, Pollard JW. Inhibiting Macrophage PI3K $\gamma$ to Enhance Immunotherapy. Cell Res (2016) 26(12):1267-8. doi: 10.1038/cr.2016.132

181. Tan B, Shi X, Zhang J, Qin J, Zhang N, Ren H, et al. Inhibition of Rspo-Lgr4 Facilitates Checkpoint Blockade Therapy by Switching Macrophage Polarization. Cancer Res (2018) 78(17):4929-42. doi: 10.1158/00085472.CAN-18-0152

182. Rabe DC, Walker ND, Rustandy FD, Wallace J, Lee J, Stott SL, et al. Tumor Extracellular Vesicles Regulate Macrophage-Driven Metastasis Through CCL5. Cancers (Basel) (2021) 13(14):1-22. doi: 10.3390/cancers13143459

183. Costa-Silva B, Aiello NM, Ocean AJ, Singh S, Zhang H, Thakur BK, et al. Pancreatic Cancer Exosomes Initiate Pre-Metastatic Niche Formation in the Liver. Nat Cell Biol (2015) 17(6):816-26. doi: 10.1038/ncb3169

184. von Moos R, Costa L, Gonzalez-Suarez E, Terpos E, Niepel D, Body JJ. Management of Bone Health in Solid Tumours: From Bisphosphonates to a Monoclonal Antibody. Cancer Treat Rev (2019) 76:57-67. doi: 10.1016/ j.ctrv.2019.05.003

185. Rogers TL, Holen I. Tumour Macrophages as Potential Targets of Bisphosphonates. J Transl Med (2011) 9:177. doi: 10.1186/1479-5876-9-177

186. Kimmel DB. Mechanism of Action, Pharmacokinetic and Pharmacodynamic Profile, and Clinical Applications of Nitrogen-Containing Bisphosphonates. J Dent Res (2007) 86(11):1022-33. doi: 10.1177/154405910708601102

187. Abrahamsen B. Bisphosphonate Adverse Effects, Lessons From Large Databases. Curr Opin Rheumatol (2010) 22(4):404-9. doi: 10.1097/ BOR.0b013e32833ad677

188. Li X, Valdes SA, Alzhrani RF, Hufnagel S, Hursting SD, Cui Z. Zoledronic Acid-Containing Nanoparticles With Minimum Premature Release Show Enhanced Activity Against Extraskeletal Tumor. ACS Appl Mater Interfaces (2019) 11(7):7311-9. doi: 10.1021/acsami.8b16588

189. Zang X, Zhang X, Hu H, Qiao M, Zhao X, Deng Y, et al. Targeted Delivery of Zoledronate to Tumor-Associated Macrophages for Cancer Immunotherapy. Mol Pharm (2019) 16(5):2249-58. doi: 10.1021/acs. molpharmaceut.9b00261
190. Germano G, Frapolli R, Belgiovine C, Anselmo A, Pesce S, Liguori M, et al. Role of Macrophage Targeting in the Antitumor Activity of Trabectedin. Cancer Cell (2013) 23(2):249-62. doi: 10.1016/j.ccr.2013.01.008

191. Cespedes MV, Guillen MJ, Lopez-Casas PP, Sarno F, Gallardo A, Alamo P, et al. Lurbinectedin Induces Depletion of Tumor-Associated Macrophages, an Essential Component of Its In Vivo Synergism With Gemcitabine, in Pancreatic Adenocarcinoma Mouse Models. Dis Model Mech (2016) 9 (12):1461-71. doi: 10.1242/dmm.026369

192. Belgiovine C, Bello E, Liguori M, Craparotta I, Mannarino L, Paracchini L, et al. Lurbinectedin Reduces Tumour-Associated Macrophages and the Inflammatory Tumour Microenvironment in Preclinical Models. $\mathrm{Br} \mathrm{J}$ Cancer (2017) 117(5):628-38. doi: 10.1038/bjc.2017.205

193. Paz-Ares L, Forster M, Boni V, Szyldergemajn S, Corral J, Turnbull S, et al. Phase I Clinical and Pharmacokinetic Study of PM01183 (a Tetrahydroisoquinoline, Lurbinectedin) in Combination With Gemcitabine in Patients With Advanced Solid Tumors. Invest New Drugs (2017) 35 (2):198-206. doi: 10.1007/s10637-016-0410-3

194. Demetri GD, von Mehren M, Jones RL, Hensley ML, Schuetze SM, Staddon A, et al. Efficacy and Safety of Trabectedin or Dacarbazine for Metastatic Liposarcoma or Leiomyosarcoma After Failure of Conventional Chemotherapy: Results of a Phase III Randomized Multicenter Clinical Trial. J Clin Oncol (2016) 34(8):786-93. doi: 10.1200/JCO.2015.62.4734

195. Cieslewicz M, Tang J, Yu JL, Cao H, Zavaljevski M, Motoyama K, et al. Targeted Delivery of Proapoptotic Peptides to Tumor-Associated Macrophages Improves Survival. Proc Natl Acad Sci U S A (2013) 110 (40):15919-24. doi: 10.1073/pnas.1312197110

196. Scodeller P, Simón-Gracia L, Kopanchuk S, Tobi A, Kilk K, Säälik P, et al. Precision Targeting of Tumor Macrophages With a CD206 Binding Peptide. Sci Rep (2017) 7(1):14655. doi: 10.1038/s41598-017-14709-x

197. Lee C, Bae SS, Joo H, Bae H. Melittin Suppresses Tumor Progression by Regulating Tumor-Associated Macrophages in a Lewis Lung Carcinoma Mouse Model. Oncotarget (2017) 8(33):54951-65. doi: 10.18632/ oncotarget. 18627

198. Jaynes JM, Sable R, Ronzetti M, Bautista W, Knotts Z, Abisoye-Ogunniyan A, et al. Mannose Receptor (CD206) Activation in Tumor-Associated Macrophages Enhances Adaptive and Innate Antitumor Immune Responses. Sci Transl Med (2020) 12(530):1-38. doi: 10.1126/scitranslmed.aax6337

199. Vadevoo SMP, Kim J-E, Gunassekaran GR, Jung H-K, Chi L, Kim DE, et al. IL4 Receptor-Targeted Proapoptotic Peptide Blocks Tumor Growth and Metastasis by Enhancing Antitumor Immunity. Mol Cancer Ther (2017) 16 (12):2803-16. doi: 10.1158/1535-7163.MCT-17-0339

200. Zhang L, Qi Y, Min H, Ni C, Wang F, Wang B, et al. Cooperatively Responsive Peptide Nanotherapeutic That Regulates Angiopoietin Receptor Tie2 Activity in Tumor Microenvironment To Prevent Breast Tumor Relapse After Chemotherapy. ACS Nano (2019) 13(5):5091-102. doi: 10.1021/acsnano.8b08142

201. Wang H, Sun Y, Zhou X, Chen C, Jiao L, Li W, et al. CD47/SIRP $\alpha$ Blocking Peptide Identification and Synergistic Effect With Irradiation for Cancer Immunotherapy. J Immunother Cancer (2020) 8(2):e000905. doi: 10.1136/jitc-2020-000905

202. Tang T, Wei Y, Kang J, She ZG, Kim D, Sailor MJ, et al. Tumor-Specific Macrophage Targeting Through Recognition of Retinoid X Receptor Beta. J Control Release (2019) 301:42-53. doi: 10.1016/j.jconrel.2019.03.009

203. Ngambenjawong C, Pineda JM, Pun SH. Engineering an Affinity-Enhanced Peptide Through Optimization of Cyclization Chemistry. Bioconjug Chem (2016) 27(12):2854-62. doi: 10.1021/acs.bioconjchem.6b00502

204. Ngambenjawong C, Gustafson HH, Pineda JM, Kacherovsky NA, Cieslewicz M, Pun SH. Serum Stability and Affinity Optimization of an M2 Macrophage-Targeting Peptide (M2pep). Theranostics (2016) 6(9):140314. doi: 10.7150/thno.15394

205. Tournaire R, Simon MP, le Noble F, Eichmann A, England P, Pouyssegur J. A Short Synthetic Peptide Inhibits Signal Transduction, Migration and Angiogenesis Mediated by Tie2 Receptor. EMBO Rep (2004) 5(3):262-7. doi: 10.1038/sj.embor.7400100

206. Qian Y, Qiao S, Dai Y, Xu G, Dai B, Lu L, et al. Molecular-Targeted Immunotherapeutic Strategy for Melanoma via Dual-Targeting Nanoparticles Delivering Small Interfering RNA to Tumor-Associated Macrophages. ACS Nano (2017) 11(9):9536-49. doi: 10.1021/acsnano.7b05465 
207. Pang L, Pei Y, Uzunalli G, Hyun H, Lyle LT, Yeo Y. Surface Modification of Polymeric Nanoparticles With M2pep Peptide for Drug Delivery to TumorAssociated Macrophages. Pharm Res (2019) 36(4):65. doi: 10.1007/s11095019-2596-5

208. Ngambenjawong C, Sylvestre M, Gustafson HH, Pineda JMB, Pun SH. Reversibly Switchable, pH-Dependent Peptide Ligand Binding via 3,5Diiodotyrosine Substitutions. ACS Chem Biol (2018) 13(4):995-1002. doi: 10.1021/acschembio.8b00171

209. Jaynes JM, Lopez HW, Martin GR, Yates CC, Garvin CE. Inventorspeptides Having Anti-Inflammatory Properties Patent. US Patent 20160101150. United States Patent US 9,492.499 B2 (2016).

210. Lepland A, Asciutto EK, Malfanti A, Simón-Gracia L, Sidorenko V, Vicent MJ, et al. Targeting Pro-Tumoral Macrophages in Early Primary and Metastatic Breast Tumors With the CD206-Binding mUNO Peptide. $\mathrm{Mol}$ Pharm (2020) 17(7):2518-31. doi: 10.1021/acs.molpharmaceut.0c00226

211. Asciutto EK, Kopanchuk S, Lepland A, Simón-Gracia L, Aleman C, Teesalu T, et al. Phage-Display-Derived Peptide Binds to Human CD206 and Modeling Reveals a New Binding Site on the Receptor. J Phys Chem B (2019) 123(9):1973-82. doi: 10.1021/acs.jpcb.8b11876

212. Figueiredo P, Lepland A, Scodeller P, Fontana F, Torrieri G, Tiboni M, et al. Peptide-Guided Resiquimod-Loaded Lignin Nanoparticles Convert TumorAssociated Macrophages From M2 to M1 Phenotype for Enhanced Chemotherapy. Acta Biomater (2020) 133:231-43. doi: 10.1016/ j.actbio.2020.09.038

213. Atanasov G, Pötner C, Aust G, Schierle K, Dietel C, Benzing C, et al. TIE2Expressing Monocytes and M2-Polarized Macrophages Impact Survival and Correlate With Angiogenesis in Adenocarcinoma of the Pancreas. Oncotarget (2018) 9(51):29715-26. doi: 10.18632/oncotarget.25690

214. Turrini R, Pabois A, Xenarios I, Coukos G, Delaloye J-F, Doucey M-A. TIE-2 Expressing Monocytes in Human Cancers. Oncoimmunology (2017) 6(4): e1303585-e. doi: 10.1080/2162402X.2017.1303585

215. Wu X, Li Z, Yao M, Wang H, Qu S, Chen X, et al. Identification and Characterization of a Novel Peptide Ligand of Tie2 for Targeting Gene Therapy. Acta Biochim Biophys Sin (Shanghai) (2008) 40(3):217-25. doi: $10.1111 / \mathrm{j} .1745-7270.2008 .00389 . x$

216. Buss CG, Bhatia SN. Nanoparticle Delivery of Immunostimulatory Oligonucleotides Enhances Response to Checkpoint Inhibitor
Therapeutics. Proc Natl Acad Sci U S A (2020) 117(24):13428-36. doi: $10.1073 /$ pnas.2001569117

217. Zanganeh S, Hutter G, Spitler R, Lenkov O, Mahmoudi M, Shaw A, et al. Iron Oxide Nanoparticles Inhibit Tumour Growth by Inducing ProInflammatory Macrophage Polarization in Tumour Tissues. Nat Nanotechnol (2016) 11(11):986-94. doi: 10.1038/nnano.2016.168

218. Fuchs AK, Syrovets T, Haas KA, Loos C, Musyanovych A, Mailander V, et al. Carboxyl- and Amino-Functionalized Polystyrene Nanoparticles Differentially Affect the Polarization Profile of M1 and M2 Macrophage Subsets. Biomaterials (2016) 85:78-87. doi: 10.1016/j.biomaterials. 2016.01.064

219. Fu X, Yu J, Yuan A, Liu L, Zhao H, Huang Y, et al. Polymer Nanoparticles Regulate Macrophage Repolarization for Antitumor Treatment. Chem Commun (2021) 57(56):6919-22. doi: 10.1039/D1CC02678J

220. Huang Z, Yang Y, Jiang Y, Shao J, Sun X, Chen J, et al. Anti-Tumor Immune Responses of Tumor-Associated Macrophages via Toll-Like Receptor 4 Triggered by Cationic Polymers. Biomaterials (2013) 34(3):746-55. doi: 10.1016/j.biomaterials.2012.09.062

Conflict of Interest: The authors declare that the research was conducted in the absence of any commercial or financial relationships that could be construed as a potential conflict of interest.

Publisher's Note: All claims expressed in this article are solely those of the authors and do not necessarily represent those of their affiliated organizations, or those of the publisher, the editors and the reviewers. Any product that may be evaluated in this article, or claim that may be made by its manufacturer, is not guaranteed or endorsed by the publisher.

Copyright (c) 2021 Hourani, Holden, Li, Lenzo, Hadjigol and O'Brien-Simpson. This is an open-access article distributed under the terms of the Creative Commons Attribution License (CC BY). The use, distribution or reproduction in other forums is permitted, provided the original author(s) and the copyright owner(s) are credited and that the original publication in this journal is cited, in accordance with accepted academic practice. No use, distribution or reproduction is permitted which does not comply with these terms. 